\begin{tabular}{l|l|l}
$\begin{array}{l}\text { Università } \\
\text { della } \\
\text { Svizzera } \\
\text { italiana }\end{array}$ & $\begin{array}{l}\text { Facoltà } \\
\text { di scienze } \\
\text { economiche }\end{array}$ & $\begin{array}{l}\text { Center for } \\
\text { Economic and } \\
\text { Political Research } \\
\text { on Aging } \\
\text { CEPRA }\end{array}$ \\
\hline & &
\end{tabular}

V. Galasso, P. Profeta

When the state mirrors the family : the design of pension systems 


\title{
When the State Mirrors the Family: The Design of Pension Systems*
}

\author{
Vincenzo Galasso \\ Università della Svizzera Italiana, Dondena, IGIER and CEPR \\ Paola Profeta \\ Econpubblica and Dondena, Università Bocconi
}

May 2012

\begin{abstract}
We study how the prevailing internal organization of the family affected the initial design of pension systems. Our theoretical framework predicts that, in society with weak family ties, pensions systems were introduced to act as a safety net, while in societies with strong ties they replicate the tight link between generations by providing generous benefits. Using a historical classification of family ties, we show that in societies dominated by (weak ties) absolute nuclear families (f.i. Anglo-Saxon countries), safety net pension systems emerged; and viceversa in societies dominated by strong families. These results are robust to controlling for alternative legal, religious, and political explanations. Evidence on individual data confirm these findings: US citizens whose ancestors came from countries featuring strong ties (communitarian or egalitarian nuclear) families prefer to rely on the government as a provider of old age security through generous retirement benefits.

Keywords: culture; family ties, pension design.

JEL Classifications: Z10; Z13; N30; H10; H55.
\end{abstract}

\footnotetext{
*Vincenzo Galasso, Università della Svizzera Italiana, Via Buffi 6, 6900, Lugano, Switzerland; vincenzo.galasso@usi.ch; Paola Profeta, Università Bocconi, Via Roentgen 1, 20136 Milan, Italy, paola.profeta@unibocconi.it. We thank Filippo Mezzanotti and Michel Serafinelli for excellent research assistance. We thank Alberto Alesina, Guido Alfani, Maristella Botticini, Monika Butler, Pierre Cahuc, Paola Giuliano, Tommaso Nannicini, Michele Pellizzari and participants at CESifo Conference on Employment and Social Protection, Munich, NETSPAR International Workshop, Zurich, Dondena-Bank of Italy conference, Rome, 2011 NBER summer institute, Boston, CEPR public policy symposium, Zurich, Helsinki University, and Stockholm University for useful comments. We acknowledge financial support from NETSPAR. Usual disclaimers apply.
} 
"Ergo age, care pater, cervici inponere nostrae:

Ipse subibo umeris nec me labor iste gravabit.

Quo res cumque cadent, unum et commune periclum"

(Aeneis ${ }^{1}$, liber secundus)

\section{Introduction}

Institutions matter. A growing literature has emphasized the impact of pre-existing legal, political and economic institutions on economic development, income inequality, living arrangements and even fertility decisions (see, among the others, Putnam, 1993, Tabellini, 2008 and 2009, Acemoglu et al., 2001, North, 1990, La Porta et al., 1997, Fernandez and Fogli, 2009, Guiso et al., 2006). Whether these historical institutions affect social-economic outcomes through their impact on current institutions or through a less tangible, cultural transmission process is instead less understood (Tabellini, 2009).

In this paper, we focus on the role of what is arguably the primal institution: the family. We emphasize the economic relevance of the historical patterns of the within family organization. The organization of the family structure includes the relation between parents and kids, from their childhood till their parents' old age; the relation among siblings; and the relation between the family as a unit and the society at large. These primal aspects of the family organization can be transmitted over time, codified in the law, and even embedded into newly born economic institutions. Our point of departure is that when the family is substituted in one of its economic roles by a new institution, the economic organization that was prevailing within the family is likely to be adopted by the new-born institution. To study this transmission mechanism from family culture (or organization) to economic institutions, we concentrate on the impact of the family structure on the design of the most widely spread welfare state program in the world: the public pension system.

Before the introduction of public pension systems, which largely occurred between the beginning of the XX century and the aftermath of world war II, families were typically the unique providers of old-age security for their elderly members. Yet, the organization of

"Haste, my dear father, ('t is no time to wait,)

And load my shoulders with a willing freight.

Whate'er befalls, your life shall be my care;

One death, or one deliv'rance, we will share".

(Aeneas to his father Anchises, in Virgil's Aeneid, second book) 
the within-family insurance system largely differed across regions and family types. While in some countries, such as England, adults had no legal obligation to support their elderly parents, in France they were morally, but also legally reliable for their elderly parents' health and economic situations (see Twigg and Grand, 1998). In the latter case, parents could rely on their offsprings for complete old age support, to an extent that of course depended on their own and on their kids' economic conditions. In the former case, instead, upward vertical support (from the kids to their parents) was less common, and mostly consisted of a safety net, whenever parents fell into poverty. Our goal is thus to understand to what extent the principles governing the within family organization have influenced the original design of pension systems. Interestingly, those fundamental characteristics are still present in the current systems, and largely differ across countries. Did the initial design of pension systems mirror the within family organization? Did countries characterized by families providing strong vertical old age support favor the introduction of earning-related insurance schemes, which replace a large share of the workers' previous wage? And did countries characterized by weak family responsibility for the well being of the elderly endorse flat-rate pension schemes providing only an old age safety net?

To answer these fundamental questions, we introduce a two-periods OLG model that examines the link between family structure and pensions design. We consider two family structures featuring weak or strong ties, and hence different within family organizations. Pension design can be of two types: a redistributive Beveridgean scheme and an earningrelated Bismarckian system. We also study two economic and demographic scenarios. In an "old regime", family members lived close to one another and the cost of providing resources to the elderly was small. In a "new regime", arising for instance from industrialization, urbanization and similar processes, which induced nuclearization of the family, family members tend to be more spread out geographically, and the cost of transferring resources to the elderly increases. ${ }^{2}$ Our model shows that, in the "old regime", no pension system is introduced, and adults take care of their family obligations towards their parents through private transfers. In the "new regime", pensions emerge under both family types. In societies with strong ties families, a Bismarckian scheme provides comprehensive and generous benefits that come to substitute the adults-to-old-parents family transfers. Also in societies with weak ties families, pensions reflect the pre-existing family organization

\footnotetext{
${ }^{2}$ Interestingly, the timing and the degree of urbanization may depend on the strength of the family ties. In fact, in societies featuring weak families, individuals may have lower costs of moving to the cities, and the industrialization process may have begun earlier, thus creating a demand for old age pensions. Here, we disregard the timing of events, and concentrate on the original design of the pension system regardless of its year of introduction.
} 
and thus a Beveridgean system offering only a safety net emerges.

To test the predictions of our model on how the different within family organizations shape the initial pension design, we use a historical classification of medieval family types (Todd, 1983). Family organizations are divided in four types - absolute nuclear, egalitarian nuclear, authoritarian, communitarian - which deliver a complete picture of the family relationships in the world since the medieval era. Absolute nuclear families, which represent the dominating type in Anglo-Saxon countries, Holland and Denmark, display the weaker ties. The high degree of independence among family members is due to the fact that parents-adult kids cohabitation is uncommon, and parents are unconstrained in their inheritance decisions. The stronger ties are in communitarian families. Here, family constraints are tight since cohabitation is the norm and parents have to obey to strict inheritance rules, requiring equality among siblings. Egalitarian nuclear and authoritarian families represent intermediate cases of family interdependence. In egalitarian nuclear families, the parents-kids relation is shaped by strict equalitarian norms in the inheritance rules. In authoritarian families, parents have more freedom of decision, but cohabitation is the norm. We show this historical classification of the strength of the family ties to be in line with Alesina and Giuliano (2007) recent work on family types based on World Value Survey individual data. In countries characterized by strong ties (communitarian and egalitarian nuclear) families, individuals display more respect for their parents ${ }^{3}$ than in absolute nuclear, after controlling for individual characteristics.

The design of the pension system is classified according to the replacement rates, which measure the ratio between pension benefits and labor income prior to retirement, for different income levels. If a pension system replaces a constant proportion of the workers' income, these replacement rates will be roughly constant across income levels. On the other hand, they will widely differ - being higher for low-income workers, if the pension system acts as a safety net. ${ }^{4}$

Our empirical findings suggest that in countries where (weak ties) absolute nuclear families prevail, pension schemes act mainly as a flat safety net. This link between family types and pension design is robust to controlling for alternative explanations of the

\footnotetext{
${ }^{3}$ In particular, they are more likely to repond that "Regardless of what the qualities and faults of one's parents are, one must always love and respect them" rather than "One does not have the duty to respect and love parents who have not earned it by their behavior and attitudes".

${ }^{4}$ Pension schemes with an earnings-related formula are typically referred to as "Bismarckian" systems, while flat-rate ones as "Beveridgean" systems. See Disney and Johnson (2001), Conde-Ruiz and Profeta (2007), OECD(2005) for a classification of current pension systems according to their redistributive design and Conde-Ruiz and Profeta (2007), Koethenburger et al. (2008) for political-economy explanations of their different nature.
} 
introduction of the pension systems, such as legal origin, religion, urbanization and democratization of the country at the time of the introduction, current GDP, share of elderly in the population, electoral rules and forms of government. Interestingly, historical family types affect the design of the pension systems, which constitutes a persistent feature, but not their level of spending, which has instead largely changed over time.

A simple comparison may help to appreciate the relevance of the family organization in shaping the design of pension systems. Consider four, geographically close countries characterized by the same (Scandinavian) legal origin, such as Denmark, Finland, Norway and Sweden. According to Todd (1983) classification, Norway and Sweden featured authoritarian families, Finland was characterized by a communitarian family structure, while Denmark was based on absolute nuclear families. Also the design of their pension system differs. With a ratio of the pension replacement rates across income levels (respectively at $75 \%$ and at $150 \%$ of the average wage) equal to 1.6 , and an average replacement rate of $54 \%$, the weak-ties-family Denmark stands out for its safety net, highly redistributive pension system. Norway and Sweden also have somewhat redistributive (their ratio of replacement rates across income being respectively 1.25 and 1.09), but more generous systems, with an average replacement rate equal to $65.1 \%$ and to $68.2 \%$. On the other hand, Finland, which is characterized by a communitarian family structure, features a perfectly Bismarckian pension system (the ratio of replacement rates across income is equal to 1), with an average replacement rate of $78.8 \%$.

The empirical analysis on individual data confirms these cross-country results. Following a growing literature (see Fernández and Fogli, 2006, 2009, and Alesina and Giuliano, 2007, among many others), we use individual responses to questions on the role of the government in providing support to the elderly, which were available in the 1972-2008 waves of the General Social Survey (GSS). To avoid reverse causality problems, due for instance to the use of welfare state programs affecting the family organization (or type), we choose not to classify individuals into family types according to their responses to GSS questions on the importance of the family. Instead, we associate to each person the family type which was prevailing in his family's country of origin. We find that individuals whose ancestors came from countries featuring strong ties (communitarian or egalitarian nuclear) families prefer more generous state-provided retirement benefits than those from weak ties (absolute nuclear) families.

Additionally, we exploit the regional (within-country) variation in Todd (1990) classification of family types for three countries (Finland, Portugal and the UK) to test whether individuals living in different regions of the same country have different views on public 
pension policies. Using individual data from a European Value Survey question on the role of the state in pension policy, we show that individuals living in regions of the UK that feature weak ties families support individual responsibility for old age pension over state intervention, whereas those living in regions with stronger family ties favor state responsibility. In Finland and Portugal, all regions feature strong ties families - namely authoritarian and communitarian in Finland, and egalitarian nuclear and authoritarian in Portugal, and no difference emerge when comparing individuals from different regions.

A recent literature has analyzed the role of the family as a primal institution affecting economic outcomes, and its role of intergenerational transmission of culture. For instance, Alesina and Giuliano (2007) claim that the strength of family ties represents a fundamental cultural trait shaping economic behavior and attitudes. They elaborate a measure of culture based on family relationships and quantify its role in explaining important economic variables, such as the amount of home production versus market activities and the role of women. A previous argument by Reher (1998) also pointed out that family ties help explaining living arrangements and geographical mobility of young generations. Indeed, the link between family types and individual economic behavior dates back to Banfield (1958), who first used the term "amoral family" to describe the social and cultural environment that was shaping individual decisions in a small village in the south of Italy. More recently, Duranton et al. (2009) used Todd's (1990) classification of family structures to explain regional differences in economic outcomes. Algan and Cahuc (2007) shows that family culture is responsible for cross-country heterogeneity in employment rates. Alesina et al. (2010) argue that in countries with strong ties families individuals are less mobile and prefer more regulated labor market while weak ties families are associated with more flexible labor markets, which then require higher geographic mobility of workers to be efficient. ${ }^{5}$ All these papers consider the family culture to be persistent over time. Bisin and Verdier (2001) and Tabellini (2008) endogenize this cultural transformation mechanism by showing how rational, altruistic parents may optimally choose to transmit their family values to their children.

The link between family relations and welfare systems has also received a recent attention, mainly by sociologists. Focusing on Europe, Esping-Andersen (1999) argues that where family ties are stronger, social risks are typically internalized within the family by pooling resources across generations. Other authors have stressed the impact of gender

\footnotetext{
${ }^{5}$ The impact of cultural factors on individual economic decisions is also addressed by Guiso, Sapienza and Zingales (2006), who analyze as a specific example the impact of religion or ethnic origins on trust and on preferences for redistribution. See also Fernández (2007) for a survey of some of the recent empirical studies on the effects of culture on economic outcomes.
} 
culture on the welfare state (Lewis, 1992) and the role of Christian religion in European welfare state (Daly, 1997). Coleman (1988) argues that family ties can strengthen the support received by young generations from the old while, at the same time, representing an obstacle for innovation and new ideas. Finally, Pfau-Effinger (2005) emphasizes the link between culture and welfare state policies, as she argues that welfare state policies differ according to the underlying cultural model of the family, and to how much importance is attributed to the family for the production of welfare.

This paper is also related to a recent literature on the origin of welfare. According to several authors (for a discussion, see Caucutt, Cooley and Guner, 2007, and Cutler and Johnson,2004), Pay-As-You-Go pension systems that feature intergenerational transfers from workers to retirees were introduced in the western world around the period of urbanization. The rationale for the creation of a public transfer system was the rapid change from the existence of an extended family living in the same house to smaller families dislocated in many different places, due to the urbanization. In this new setup, kids became increasingly unable to look after their parents and to take care of their old age needs, and new forms of insurance had to be introduced. Yet, this theory has hard time matching the timing of the urbanization process with the introduction of social security systems (see e.g., Lindert, 1994, and Perotti and Schwienbacker, 2007). Our relation between family types and the initial design of the social security system instead does not rest on a specific date for the introduction of social security.

The paper is organized as follows: section 2 explains the model, section 3 presents the historical classification in family types based on Todd (1983), and discusses the origins of pension systems and their design; sections 4 and 5 describe our econometric analyses and results. Section 6 concludes. Proofs are in the Appendix.

\section{The Model}

We introduce a simple two-periods OLG model to analyze the link between family structure and pension design. We consider two stylized family structures: strong and weak ties family. These two structures differ in the rule defining the degree of insurance within the family. Pension design can be of two types. Bismarckian systems provide the retirees with pension benefits that are strongly linked to the individuals' previous working income. Beveridgean schemes instead feature flat pension benefits, which are largely independent of the individuals' previous contributions.

We also consider two different scenarios. In an initial "old regime", family members 
and relatives tend to live close to one another. Hence, regardless of the family structure, the cost of looking after a family member - namely the elderly - is relatively low. In a "new regime," driven for instance by industrialization, urbanization and similar processes, in which a nuclearization of the family has occurred, looking after the old has become more costly in both weak and strong ties families. ${ }^{6}$

The next section characterizes these two family structures. Section 2.2 describes the two types of pension design and the political process leading to the determination of the pension design and of the level of pension spending. The economic and political decisions taken by the adults in the strong family types, both in the "old" and the "new" regimes are examined in section 2.3. An analysis of these decisions in weak families follows.

\subsection{Family structures}

In every period, two generations of equal size are alive: adult and old. Adults earn an income $y_{i} \in\left[y_{l}, y_{u}\right]$. Individuals hence differ in their income, which is distributed in the population according to a cumulative distribution function $F\left(y_{i}\right)$, with median income, $y_{M}$, and mean income, $\bar{y}$. Children are assumed to have the same income as their parents, so we consider dynasties of equal income, $y_{i}$. Adults may save, $s_{i}$, in order to increase the resources in old age. Returns from savings, denoted by $R$, are uncertain. With a probability $\rho$, individuals enjoy high returns, $R=\bar{R}$, while with probability $(1-\rho)$ the returns are low, $R=\underline{R}$, with $\bar{R}>\underline{R}$. It is convenient, but not crucial, to assume that $\underline{R}=0$. Thus, the average returns from savings are $\rho \bar{R}$. Old individuals do not work. They obtain the returns from their savings, $R s_{i}$, and may receive a pension, $P_{i}$.

We consider a logarithmic utility function in youth and old age consumption. A type- $i$ individual born at time $t$ has the following utility function

$$
U\left(c_{i, t}^{A}, c_{i, t+1}^{o}\right)=\ln c_{i, t}^{A}+\beta \ln c_{i, t+1}^{o}
$$

where superscripts indicate the generation (adult, old), subscripts refer to the income type and to the time period and $\beta$ is the subjective discount factor. Economic decisions are taken by the adults.

In strong ties families, the adults have a moral (or perhaps even legal) obligation to provide an adequate level of consumption to the old. We capture this obligation by

\footnotetext{
${ }^{6}$ The family type may also affect individual mobility (see Alesina et al., 2010) and hence the timing of urbanization. Eventually, however, most countries have reached a certain degree of urbanization and pension system have been introduced.
} 
imposing a constraint on the old consumption, as a function of the adults income:

$$
c_{i, t}^{o} \geq \gamma y_{i}
$$

Hence, regardless of the elderly private wealth, adults have to make sure that the elderly family members enjoy a substantial consumption level, corresponding to a (large) percentage $\gamma$ of their income, $y_{i}$. This is to capture the idea that in a family with strong ties, adults have to guarantee to their parents a standard of living, which is similar to their own. Hence, the adults' budget constraint in a strong ties family is:

$$
c_{i, t}^{A}+s_{i, t}=\left\{\begin{array}{cc}
y_{i}\left(1-\tau_{t}\right) & \text { if } P_{i, t}+s_{i, t-1} R_{t} \geq \gamma y_{i} \\
y_{i}\left(1-\tau_{t}\right)-\left(1+\phi^{j}\right)\left(\gamma y_{i}-P_{i, t}-s_{i, t-1} R_{t}\right) & \text { otherwise }
\end{array}\right.
$$

where $\tau_{t}$ is a proportional tax paid by the adults on their income, $P_{i, t}$ is the pension benefits received by a type- $i$ old individual at time $t$, and $\phi^{j}$ represents the deadweight cost of providing private resources to the old family members in the old $(j=O R)$ and in the new regime $(j=N R)$.

This cost of providing resources to the parents is assumed to be negligible in the old regime, $\phi^{O R}=0$, but to be positive in the new regime, $\phi^{N R}=\phi>0$, where families are more geographically disperse.

In families with weak ties, adults still have a moral (or legal) obligation, but only to keep the old family members above a subsistence consumption level. This limited degree of within family insurance is represented by the following constraint on old age consumption:

$$
c_{i, t}^{o} \geq \delta \bar{y}
$$

where $\bar{y}$ is the average income in the economy, and $\delta<1$ defines the poverty level with respect to the average income. The adults' budget constraint in a weak ties family becomes:

$$
c_{i, t}^{A}+s_{i, t}=\left\{\begin{array}{cc}
y_{i}\left(1-\tau_{t}\right) & \text { if } P_{i, t}+s_{i, t-1} R_{t} \geq \delta \bar{y} \\
y_{i}\left(1-\tau_{t}\right)-(1+\phi)\left(\delta \bar{y}-P_{i, t}-s_{i, t-1} R_{t}\right) & \text { otherwise }
\end{array}\right.
$$

\subsection{Pension Design}

We consider two stylized PAYG pension schemes. In both systems, adults pay a proportional tax $\tau_{t}$ on their income, $y_{i}$, and these revenues are entirely used to provide pension benefits, $P_{i, t}$, to the elderly. Hence, these schemes are assumed to be budget-balanced. 
Moreover, pensions are distortionary, as captured by a parameter $\varepsilon>0$, which measures the deadweight cost of using pensions.

In a Bismarckian system, pension benefits are proportional to the individuals' income:

$$
P_{i, t}^{B I S}=\tau_{t}(1-\varepsilon) y_{i}
$$

Hence, all individuals receive the same pension replacement rate - as defined by the ratio of current pension to previous income - which is equal to $R R_{i}^{B I S}=P_{i t}^{B I S} / y_{i}=\tau_{t}(1-\varepsilon)$.

In a Beveridgean scheme, pension benefits are instead flat, that is, they are not related to the individuals' income, but rather to the average income in the economy, as defined by the following expression:

$$
P_{i, t}^{B E V}=P_{t}^{B E V}=\tau_{t}(1-\varepsilon) \bar{y}
$$

This scheme thus features redistribution from high to low income individuals. In fact, the pension replacement rate is equal to $R R_{i}^{B E V}=P_{i, t}^{B E V} / y_{i}=\tau_{t}(1-\varepsilon) \bar{y} / y_{i}$, and is thus decreasing in income.

Notice that, regardless of the pension design, the return from pensions for the average individual (i.e., the individual with the average income) at steady state, that is, for a constant tax rate, is equal to $1-\varepsilon$. In line with the existing literature on social security, we assume the average return from private savings to be larger than this (safe) average return from pensions; hence, $\rho \bar{R}>1-\varepsilon$.

The decisions over the design - whether Bismarckian or Beveridgean - and the size - i.e., the tax rate - of the pension system are taken sequentially at majority voting. In every period, individuals first decide whether to have a Bismarckian or a Beveridgean scheme in place, and then which social security tax rate to impose. Political players (i.e., voters) are assumed to be all adult individuals. Current decisions over the design and the size of the pension system do not bind future generations, but can rather be modified by future adults.

At this juncture, it is convenient to lay down some assumptions on the income distribution and on the pension system that will be used in the next sections.

Assumption $1 y_{M} \in[(1-\varepsilon) \bar{y}, \bar{y}]$

This assumption acknowledges the income distribution to be skewed, but at the some time, it requires this distribution not to be so disperse as to induce pension spending for pure redistributive reasons.

Assumption 2 For $\phi>0$, i.e., in the new regime, $(1-\varepsilon)(1+\phi)>1$ 
This assumption restricts the private intra-family transfers in the new regime to be more costly for the adult members of the average family than using the distortionary pension system. Thereby, it provides a rational for pension transfers to be introduced in the new regime.

In the following sections, we analyze the economic and political decisions taken in families with strong and weak ties in the "old" and in the "new" regime.

\subsection{Strong ties families}

In strong ties families, adult individuals are required to ensure to the elderly members of the family an adequate level of consumption, in line with the family income. The saving decisions by the adults hence entail a strategic component. In fact, adults anticipate that if they will lack a sufficient amount of old age resources (due to low savings or to a bad realization of the returns), the future generation will have to step in and provide them with a consumption at least equal to $\gamma y_{i}$. As a result, adults will only be willing to save if the level of old age consumption ensured by the family, as measured by $\gamma$, is sufficiently small (see Proposition 2).

To analyze the political choice over the design and the size of the pension system, it is convenient to consider first the case of no private old age resource. This may occur either because the elderly decided not to save when they were adults, or because of a bad realization of the returns. Current adults have to choose whether to take care of the consumption of the elderly members of the family through a pension system or through private transfers. In taking this political decision, they understand that their choice does not bind future voters on the pension system that they may enjoy during their old age.

In every period, individuals decide first whether to have a Bismarckian or a Beveridgean scheme in place, and then which social security tax rate to support. It is thus convenient to analyze the problem backward. We begin by examining the political equilibrium tax rate respectively under a Bismarckian and a Beveridgean system; and we then turn to the pension design decision.

\section{Bismarckian System}

In a Bismarckian system, pension benefits are proportional to family income. Hence, a tax rate of $\tau=\gamma /(1-\varepsilon)$ would command an individual pension benefit of $P_{i, t}^{B I S}=\gamma y_{i}$, which would allow elderly individuals in every family to reach their family consumption level, $\gamma y_{i}$. It is easy to see that using a Bismarckian pension system is more convenient than the alternative family transfers in the new regime, i.e., when $(1-\varepsilon)(1+\phi)>1$; 
but not in the old regime. Hence, a Bismarckian system, characterized by $\tau=\gamma /(1-\varepsilon)$, would only be supported in the new regime.

\section{Beveridgean System}

In a Beveridgean system, pension benefits are instead flat. Therefore, the tax rate that provides enough pension benefits to an elderly family member to finance her family consumption level $\left(\gamma y_{i}\right)$ depends on the family income. In particular, we have $\tau_{i}=$ $\gamma y_{i} /(1-\varepsilon) \bar{y}$ in order to achieve $P_{i}^{B E V}=\tau_{i}(1-\varepsilon) \bar{y}=\gamma y_{i}$. A pension system with this tax rate, $\tau_{i}$, is preferred to private family transfers by the individuals with an income below the following threshold: $y_{i}<(1-\varepsilon) \bar{y}$. Hence, according to assumption 1 , in the old regime a majority of the individuals prefers to finance the consumption of their family old members through private transfers, and no Beveridgean pension system emerges.

In the new regime, instead, a majority of the individuals would prefer their own most preferred tax rate, $\tau_{i}$, to the private transfer. Interestingly, this tax rate is increasing with the income of the adults as long as $y_{i}<(1-\varepsilon)(1+\phi) \bar{y}$. Above this threshold, adult individuals prefer to use the private family transfer and vote for a zero tax rate, due to the redistributive nature of the pension scheme. As described in the proposition below, in the new regime an "ends-against-the-middle" equilibrium thus emerges, in which high-income (i.e., with $\left.y_{i}>(1-\varepsilon)(1+\phi) \bar{y}\right)$ and low income adults support low pension spending (or no spending), while middle income adults prefer higher pensions.

Proposition 1 Under the "old" regime, a Beveridgean pension system is not supported. Under the "new" regime, in absence of private old-age wealth, $s_{i} R=0$, a Beveridgean pension system emerges as a political economic equilibrium of a voting game and is characterized by a tax rate $\tau=\frac{\gamma y_{M V}}{(1-\varepsilon) \bar{y}}$, where $y_{M V}$ is such that $F\left(y_{M V}\right)=F(\widetilde{y})-\frac{1}{2}$, and $\widetilde{y}=(1-\varepsilon)(1+\phi) \bar{y}$.

\section{Pension Design}

In the old regime, individuals always prefer to ensure consumption to their old family members through private within family transfer; and thus no pension system will emerge. In the new regime, introducing a pension system becomes a more convenient option, due to the increase in the cost of within family resource provision (see assumption 2). Yet, will adult individuals prefer the more generous Bismarckian system (notice that $\tau^{B I S}>\tau^{B E V}$ ) or the more redistributive Beveridgean scheme?

Low income individuals $\left(y_{i}<y_{M V}\right)$ clearly prefer a redistributive Beveridgean system, which allows them to transfer part of the cost of supporting their parents' consumption 
to the richer adults. By the same argument, high income individuals prefer instead a Bismarckian system. For middle income individuals - for instance with $y_{i} \in\left(y_{M V}, y_{M}\right)-$ the Beveridgean system does not provide enough resources to ensure the required family level of old age consumption, $\gamma y_{i}$, and the adults have to supplement the pension benefits with family transfers. This creates a clear trade-off. On one hand, these adults benefit from the redistributive component of the Beveridgean system; on the other hand, however, they have to use the less efficient family transfer to top-up their parents' insufficient pension benefits. As characterized in the next proposition, an income threshold exists above which adult individuals prefer a Bismarckian system, and viceversa.

Proposition 2 Under the "old" regime, no pension system is in place. Under the "new" regime, in absence of private old age wealth, $s_{i} R=0 \forall i$, (i) if $y_{M} \geq \widehat{y}=\frac{\widetilde{y}}{\tilde{y}+y_{M V}-\bar{y}} y_{M V}$, a Bismarckian pension system with $\tau^{B I S}=\frac{\gamma}{(1-\varepsilon)}$ emerges, and it is supported in all future periods if $\gamma \geq \frac{\beta \rho \bar{R}}{(1+\beta \rho)\left(1+\frac{1}{\beta \rho}\right)+\beta \rho \bar{R} /(1-\varepsilon)}$; and (ii) if $y_{M}<\widehat{y}$, a Beveridgean pension system with $\tau^{B E V}=\frac{\left(y_{M V}\right.}{(1-\varepsilon) \bar{y}}$ emerges, and it is supported in all future periods if $\gamma \geq$ $\frac{\beta \rho \bar{R}}{(1+\beta \rho)\left(1+\frac{1}{\beta \rho}\right)+\beta \rho \bar{R} y_{M V} /(1-\varepsilon) \bar{y}}$.

The above proposition suggests that, in the new regime, when the income distribution is not as skewed as to lead to a large demand for redistribution, a Bismarckian system emerges that provides the elderly - who lack private wealth - with the exact amount of resources to enjoy the family ensured level of consumption. If the consumption level guaranteed by the family is sufficiently large, as summarized by the parameter $\gamma$, adults individuals will choose not to save for future consumption, and will thus reach old age with no private wealth, $s_{i} R=0$. A corresponding Bismarckian system will thus continue to be supported. If instead, the income distribution is sufficiently spread out, the demand for redistribution dominates, and a Beveridgean system emerges, which will continue to be supported if individuals - as previously explained - will choose not to save for future consumption.

\subsection{Weak ties families}

In weak ties families, adult individuals are required to guarantee to their family elderly members only a subsistence consumption level, $\delta \bar{y}$, which is independent of the adults' income. Providing resources to the elderly is costly in the "new" regime $(\phi>0)$, but not in the "old" regime.

As before, adults act strategically. They anticipate that if they choose not to save, they will reach old age with no private wealth and will thus be supported by their future 
adult family members, who will ensure them the subsistence consumption level, $\delta \bar{y}$. Thus, adults will only be willing to save if this subsistence consumption level is low enough, given their family income (see Proposition 3 ).

As in section 2.3, we begin our analysis of the political choice over the design and size of the pension system by focusing on the case of no private old age resource. We study the problem backward: first, we analyze the political equilibrium tax rate respectively under a Bismarckian and a Beveridgean system, and we then turn to the pension design decision.

\section{Bismarckian System}

In a Bismarckian system, pension benefits are proportional to family income: $P_{i}^{B I S}=$ $\tau(1-\varepsilon) y_{i}$. Yet, adult individuals only need to guarantee the constant subsistence consumption level, $\delta \bar{y}$, to their parents. Hence, adults of different income will choose different tax rate to achieve this goal. More specifically, every type- $i$ individual will support a tax rate $\tau_{i}=\delta \bar{y} /(1-\varepsilon) y_{i}$ in the "new" regime, since $(1-\varepsilon)(1+\phi)>1$, while no Bismarckian pension system would be supported in the "old" regime. In the new regime, since the most preferred tax rate is decreasing in income, the political equilibrium Bismarckian tax rate chosen by the median income adult will correspond to $\tau=\delta \bar{y} /(1-\varepsilon) y_{M}$.

\section{Beveridgean System}

In a Beveridgean system, pension benefits are instead flat; and so is the subsistence consumption level that has to be provided to the elderly members in the family. Hence, a tax rate equal to $\tau=\delta /(1-\varepsilon)$ would command an individual pension benefit of $P_{i, t}^{B E V}=$ $P_{t}^{B E V}=\delta \bar{y}$, thereby allowing elderly individuals in every family to meet the subsistence consumption level. Using this Beveridgean pension system is more convenient than private family transfers for low income individuals, with an income such that $y_{i}<(1-\varepsilon)(1+\phi) \bar{y}$, and viceversa for richer adults. Since $(1-\varepsilon)(1+\phi)>1$, and $y_{M}<\bar{y}$, in the "new" regime, the median income voter will support the system, and a Beveridgean system with $\tau=\delta /(1-\varepsilon)$ will emerge. No Beveridgean pension system would emerge in the old regime, since, by assumption $1, y_{M}<(1-\varepsilon) \bar{y}$.

\section{Pension Design}

In the old regime, individuals always prefer to use private, within family transfers to ensure the subsistence consumption level to their old family members, and thus no pension system is introduced. In the new regime, pension systems become more convenient, due to the higher cost of providing resources within the family, and all individuals prefer to support the Beveridgean system. To see this, notice that the equilibrium tax rate emerging in a Bismarckian system is higher than the one under a Beveridgean system. 
Yet, while in the Beveridgean system, for all families, the pension benefits cover exactly the subsistence consumption level, $P_{t}^{B E V}=\delta \bar{y}$; in the Bismarckian system the subsistence level (and indeed an even higher consumption) is ensured only to those individuals whose income is above the median, since $P_{i}^{B I S}=\tau(1-\varepsilon) y_{i}=\delta \bar{y}\left(y_{i} / y_{M}\right)$. Poorer individuals those with below median income - have to top-up the Bismarckian pensions with costly private transfers to their parents. The Beveridgean system is thus supported by all adults. Below median income adults contribute less and obtain a higher pension for their parents; whereas above median income adults obtain the same subsistence consumption level for their parents in both systems, but pay lower contributions in the Beveridgean system.

The next proposition summarizes these results.

Proposition 3 Under the "old" regime, no pension system is in place. Under the "new" regime, in absence of private old age wealth, $s_{i} R=0 \forall i$, a Beveridgean pension system with $\tau^{B E V}=\frac{\delta}{(1-\varepsilon)}$ always emerges, and it is supported in all future periods if $y_{M} \leq y_{S}=$ $\frac{\delta \bar{y}(1+\beta \rho)\left(1+\frac{1}{\beta \rho}\right)}{\beta \rho \bar{R}\left(1-\frac{\delta}{1-\varepsilon}\right)}$. If $y_{M}>y_{S}$, for $R=\bar{R}$, there is no pension spending, $\tau=0$.

The above proposition suggests that, in the new regime, when individuals have no private old age wealth, $s_{i} R=0$, a Beveridgean pension system dominates. In a society of weak ties families, with a Beveridgean system in place, medium and high income adults individuals $\left(y_{i}>y_{S}\right)$ find still convenient to save in order to increase their old age consumption in the good state (i.e., when $R=\bar{R}$ ), while poorer individuals do not. If a good state actually occurs, middle and high income adults individuals $\left(y_{i}>y_{S}\right)$ will thus have enough old age private resources to cover the subsistence consumption level, and no family intervention is required. Hence, if the median voter is sufficiently poor $\left(y_{M} \leq y_{S}\right)$, her parents will not have enough old age private wealth and a Beveridgean pension system will be supported. On the other hand, if the median voter is sufficiently rich $\left(y_{M}>y_{S}\right)$, no pension system will be supported, and low income individuals will have to finance their parents' subsistence consumption level with private transfers. In this scenario, $\left(y_{M}>y_{S}\right)$, the system will oscillate between $\tau=\tau^{B E V}$ when $R=0$, and $\tau=0$ when $R=\bar{R}$.

The analysis of the family organization in the "old" and "new" regime for the strong and weak ties families provides interesting insights. While no pension system will exist in the "old" regime, a pension scheme typically emerges under the "new" regime. Societies with weak ties families always support less generous, yet more redistributive Beveridgean schemes; whereas Bismarckian systems can only appear in societies with strong ties families. In the empirical session, we will concentrate on a particular measure of the design of 
pension systems: the ratio between replacement rates at different incomes. This is given by $M=R R_{i} / R R_{j}$ with $i \neq j$, where $R R_{i}=P_{i} / y_{i}$. In a pure Bismarckian system, where $P_{i}=\tau(1-\varepsilon) y_{i}$, this ratio is equal to one, $M^{B I S}=1$. In a pure Beveridgean system, instead, where $P_{i}=\tau(1-\varepsilon) \bar{y}$, this measure is $M^{B E V}=R R_{i} / R R_{j}=y_{j} / y_{i}$. Hence, for instance, the ratio between replacement rates at $75 \%$ of the average income and at $150 \%$ of the average income should be equal to 2 , as $M^{B E V}=1.5 / .75=2$.

\section{Historical perspectives on family ties and pension system design}

\subsection{Family types}

Characterizing the internal organization of the family, the relations between parents and children, among children, and between the family and the society at large, represents a difficult task. A recent literature (see Alesina and Giuliano, 2007) has used survey data on individual responses to questions on the relevance of the family, on the time spent with relatives, and on living arrangements to provide a quantitative measure of these family ties. Yet, while current relations within and across families are certainly shaped by cultural factors, they are also largely influenced by the incentives provided by economic and legal institutions, such as labor market regulations, tax code and the welfare state. To evaluate the primal effect of the family organization on the initial design of the welfare state, we thus need to use measurements of the family organization dating back to periods prior to the introduction of welfare state policies. A historical classification of family ties is in Todd (1983), who used historical monographs sometimes dating back more than 500 years, to compile a geographical mapping of family ties. We consider four family types ${ }^{7}$ (see figure 1):

- Absolute nuclear families are characterized by (i) non-cohabitation between parents and adult children (children typically leave their family after their adolescence, form their own family and become independent); (ii) lack of stringent inheritance rules; and (iii) exogamous marriage relationships. These families nurture individualism. Every person is independent, and has to rely mainly on his/her own individual effort. This clearly implies total independency of children from their parents, and viceversa. The choice of taking

\footnotetext{
${ }^{7}$ In Todd (1990) and then in Duranton (2009), a finer geographical mapping with a classification at regional level is provided. We will recur to this more detailed mapping at the end of session 5 when using individual European Value Survey (EVS) data. For the other empirical analyses, we adopt the national mapping, in which a country is classified according to the type that dominates in most regions.
} 
care of old-age parents becomes a subjective decision, rather than a generalized, codified value. As parents have no obligation to support their adult children, kids may in turn also choose whether to take care of old parents or not, and to what extent. Anglo-Saxon countries, Holland and Denmark belong to this group;

- Egalitarian nuclear families feature (i) no cohabitation of parents and adult children, (ii) exogamy, but (iii) the independence among generations is weaker than in the previous case. In fact, parents are constrained by precise inheritance rules, based on the principle of equality among siblings. This family welfare context favors the emergence of ideologies of "universalism", which recognize the value of equality, often in contrast to individualism. Egalitarian families encourage the persistence of stronger relations between parents and children. Moreover, to the extent that parents have a (moral or legal) obligation not to favour a kid over the others in their inheritance decisions, all children become responsible for their old-age. Mediterranean countries (France, Italy, Spain, Greece), Portugal, Romania, Poland, Latin America (apart from Cuba) and Ethiopia are in this group;

- Stem or authoritarian families are based on cohabitation of parents and adult children (sons typically remain in their parents' home and are subject to a vertical hierarchical structure). Rules and social norms are transmitted across generations. However, parents are largely independent from codified norms in their inheritance decisions, and the principle of equality among children is typically not recognized. Germany, Austria, Sweden, Norway, Czech Republic, Belgium, Luxembourg, Scotland, Ireland, Japan, Korea, Israel and Gitans populations are characterized by this family structure;

- Communitarian families are based on cohabitation, and parents are bind to equality among siblings in the inheritance rules. These two features minimize individualism and create strong family ties. This system was in place in Russia, Yugoslavia, Slovak, Bulgaria, Finland, Hungary, Albania, Baltic republics, Centre of Italy, China, Vietnam, Cuba, Indonesia and India.

Todd's historical classification of family types is simple, but, at the same time, it captures those aspects of the intergenerational family organization that are crucial to understand the different incentives for the early design of the pension systems. In absolute nuclear families, the principle of independence among family members dominates, and adults thus have little responsibility for the well-being of their elderly parents. In the (strong ties) communitarian and, to a lesser extent, in egalitarian nuclear and in authoritarian families, children have instead a moral (or even legal) obligation to support their parents in old age. To relate this historical classification to the current literature on family culture, we compare it to the analysis of family ties in Alesina and Giuliano (2007). They 
use three individual questions from the World Value Survey: (i) How family is important in life? the answer ranging from 1, "very important", to 4, "not at all important"; (ii) Choose between A (corresponding to the score of 0 ): "Regardless of what the qualities and faults of one's parents are, one must always love and respect them" and B (score equals 1): "One does not have the duty to respect and love parents who have not earned it by their behavior and attitudes"; (iii) Choose between A (score equals 0) "Parents' duty is to do their best for their children even at the expense of their own well-being" and B (score equals 1) "Parents have a life of their own and should not be asked to sacrifice their own well-being for the sake of their children". To compare their current measures of family ties based on these questions with Todd's historical classification we estimate the following simple model:

$y_{i}=\alpha+\beta_{1} X_{i}+\beta_{2} C O M M U N I T Y_{i}+\beta_{3} A U T H O R I T A R I A N_{i}+\beta_{4} E_{\text {EALNUCLEAR }}+\varepsilon_{i}$

where $y_{i}$ is the score attributed to the answer that individual $i$ gives to each of the three questions (respectively in column 1,2 and 3), $X_{i}$ is a set of individual controls (age, age squared, income, education, political views) and a dummy variable controls for the dominant level of family organization in the country of the respondent with absolute nuclear families being the excluded category. Table 1 shows the correlation between Todd (1983) and Alesina and Giuliano (2007) classifications. Todd's classification plays no role in explaining current responses on the importance of the family (column 1). However, stronger (current) kid-to-parents links (see column 2) are associated with communitarian and egalitarian nuclear families as compared to absolute nuclear families. Finally, column 3 describes the downward vertical ties from parents to kids, where authoritarian and communitarian families are characterized by the prominent role of the parents. In line with Todd's historical classification, Alesina and Giuliano current survey data thus confirm that stronger upward vertical ties are featured in communitarian and egalitarian nuclear families.

\subsection{The design of pension systems}

In the western world, public pension systems were initially introduced between the end of the XIX century and the end of World War II. Besides their financing method - PAYG, FF or mixed- ever since their introduction, pension systems have largely differed in their design, generosity and coverage. The two polar cases are represented by the so-called Bismarckian and the Beveridgean systems. ${ }^{8}$ A Bismarckian scheme covers all the workers,

\footnotetext{
${ }^{8}$ The names "Bismarckian" and "Beveridgean" date back respectively to the origin of the pension system in Germany and to the system proposed few decades later by the Beveridge report in the United Kingdom.
} 
who have contributed to the system throughout their working life. It provides them with a pension benefit that is strictly related to these contributions, and typically replaces a large share of the workers' previous wage. The replacement rates, i.e., the ratio of postretirement pension benefits to pre-retirement earnings, are thus approximately constant across individuals of different incomes, and the system entails no intragenerational redistribution. In Beveridgean systems, contributions are largely proportional to earnings but benefits are instead almost flat; thus, intragenerational redistribution is large. Beveridgean systems have more universal coverage; they still base their financing on social security contributions, but typically the pension benefit does not replace a large share of the worker's previous wage. As such, they mainly constitute a safety net that ensures enough retirement income to low-income workers to cover their pensions wage, while providing a low replacement of their previous wage to middle and high income workers.

To measure the design of the pension system, we thus consider the difference in the replacement rates across individuals of different income groups. Large differences in the replacement rates - with high values for low-income individuals and viceversa - identify pension systems that only act as a safety net, and should thus be associated with weak ties families; and viceversa for constant replacement rates. As discussed in the next section, we only have current measures of the replacement rates - namely around the year 2000 . Hence, for some countries, such as Germany, more than hundred years have passed since the initial design of the pension systems. Fortunately, this design has been rather persistent over time. In fact, while the size of pensions changes rapidly over years, depending on demographic, economic and political circumstances (see Galasso, 2006), the redistributive design has proven to be much more stable. For instance, the United Kingdom is still an example of a flat-rate pension system, while Germany, Italy and France have remained earnings-related. For a sample of 20 OECD countries, Krieger and Traub (2008) find no significant evidence of a change in the intragenerational redistribution in PAYG systems. Some examples suggest that each scheme may actually have accentuated its original design: Bismarckian systems have become more Bismarckian and analogously for Beveridgean schemes. Italy, for instance, has implemented reforms which have strengthened the earning-related design, by shifting from a defined benefit formula for calculating pensions to a notional defined contribution, which features a complete link between contributions and benefits, and entails almost no intragenerational redistribution. On the opposite, in the last few years the UK program has become even more redistributive: rich

In the first pension system, created in Germany by Bismarck in 1881, benefits were earning-related. The Beveridge report, published in 1942 in the UK, introduced the alternative idea of a minimum system, i.e., a system with flat-rate benefits for qualified retirees. 
individuals may 'contract out' of the public system and enjoy a reduction of the contribution rate, while the State Second Pension (S2P) scheme introduced in 2002 reinforced the safety net nature of the system.

\subsection{Alternative determinants of pension design}

Our model at section 2 highlights the existence of a transmission mechanism from preexisting family organizations to the original design of pension systems. Pension systems were introduced to provide old-age support, which was previously supplied within the family, and they were designed to mirror the same organization that was prevailing within the family. Hence, where families characterized by weak ties among generations and strong independence within the family, such as Todd's absolute nuclear families, prevail, pension systems feature only a basic safety net, and are not compelled to ensure a complete provision of the elderly retirement income.

Besides family organizations, there may be alternative determinants of the main features of the welfare state, and alternative mechanisms of transmission from pre-existing conditions to the welfare state. The literature has focused in particular on the role of religion, democratization, urbanization and legal origins. Flora $(1983,1987)$ argues that the welfare state emerged under the process of secularization, i.e. the decline of religion on human conduct, and the influence of Protestantism. When religious institutions lost their dominance over society and in non-religious roles, and people reduced their religious practices and beliefs, the state replaced the church in the "public" spheres. Protestantism favored the development of the welfare state, in opposition to Catholicism, since the former encouraged the mobilization of lower income levels into mass politics and reduced the power of the church into the public sphere, while the latter continued to be dominated by the conflict between state and church. ${ }^{9}$ This contrast between Protestant and Catholic countries helps also to explain the differences in characteristics of the welfare states (such as the level of centralization and the degree of state intervention). ${ }^{10}$ Since the diffusion

\footnotetext{
${ }^{9}$ The relation between religion and in general socio-economic transformations was first identified by Weber (1905), who linked the Protestant Reform to the modern capitalism. Guiso et al (2003) find that religious beliefs, especially Christian religions, are associated with growth enhancing economic reforms. See also McCleary and Barro (2006).

${ }^{10}$ Recently, van Kersbergen and Manow (2009) reconsidered the role of Protestantism, and showed that Reformed Protestantism substantially delayed and restricted modern social policy, while the Lutheran state churches positively contributed to the introduction of social protection programs. They also argue that the interaction between religion and electoral rules produced different political class coalitions sustaining different welfare regimes.
} 
of religion has proved very persistent, this original effect may continue to shape current welfare state systems.

Democratization may represent an alternative mechanism. According to the modernization theory (Lipset, 1959), the introduction of the welfare state was due to the growing needs for social policy, social and economic equality and security, created by the industrialization. In urban, richer societies, the demand for welfare state increases. Moreover, the process of economic modernization promotes also the foundation and the consolidation of democracies. ${ }^{11}$ In democracies, poor individuals take part in politics and, as a consequence, policies favouring these individuals and promoting equality, such as redistributive policies and welfare state may emerge (Acemoglu and Robinson, 2006; Boix, 2003). Thus, democratic countries tend to have larger welfare states ${ }^{12}$.

Legal origins may also shape the pre-existing context in which pension systems were introduced. According to La Porta et al. (1997) legal origins are a good proxy for financial development. As argued by Pinotti (2009), more financial development implies less PAYG social security and viceversa, thus establishing a causal relationship from pre-existing legal origins and the size and features of the pension system (see also Perotti and Schwienbacher, 2007).

Finally, Persson and Tabellini (2004) suggest that old age spending may also depend on electoral rules (majoritarian/proportional) and forms of government (presidential/parliamentary). In particular, presidential regimes tend to induce smaller public sectors, while proportional elections lead to higher, but less targeted government spending, and to larger budget deficits.

In the next section, we will test the validity of the transmission mechanism running from family types to pension's design against these alternative channels.

\section{The Cross Country Analysis}

\subsection{Data and empirical specification}

We aim to test the effect of the pre-existing family organization, in particular its vertical kids-to-parents transfer structure, on the initial design of pension systems around the world. To characterize the different family organizations, we consider Todd's classification described at section 3.1 for a set of 85 countries, as shown at figure 1 . We

\footnotetext{
${ }^{11}$ Clearly, the interaction between modernization and democratization is a two-way relation and it is difficult to disentangle the correct direction of causality, as economic development may favor democracy, but also stable democracy may lead to economic growth.

${ }^{12}$ See Mulligan, Gill and Sala-i-Martin (2010) for a critical appraisal of this argument.
} 
use different measures to identify the initial design of the pension system. Since Bismarckian systems provided high replacement rates that are constant across income groups, while in Beveridgean systems the replacement rates vary widely across income, we identify the design of the pension scheme with the ratio between replacement rates (the ratio of post-retirement pension benefits to pre-retirement earnings) at different levels of income. Higher ratios identify a safety net scheme that provides high replacements to low-income individuals, and low to the others. We also use a direct measure of the current replacement rate for an individual with the average wage in the economy. Higher replacements are associated with more generous pension for the retiree, and thus indicate that the system provides more than just a safety net. Pension coverage, defined as the share of population between 15 and 64 years old that is covered by the pension system, captures the diffusion of the system among the population. System providing only a safety net typically feature high coverage, and yet are associated with lower spending. Pension expenditure as a percentage of GDP is also considered as a dependent variable. For these pension variables, we consider the available data around the year 2000. While the redistributive design of the pension systems has been rather stable since their introduction, and thus these recent values may be a good proxy for the initial design, current coverage and pension spending is largely determined by current demographic, economic and political processes.

We estimate a simple cross country model:

$$
\begin{aligned}
y_{i}= & \alpha+\beta_{1} C O M M U N I T A R I A N_{i}+\beta_{2} \text { AUTHORITARIAN } N_{i}+\beta_{3} E G A L N U C L E A R_{i}+ \\
& \beta_{4} O E C D_{i}+\beta_{5} L A A M_{i}+\beta_{6} A F R I C A_{i}+\beta_{7} X_{i}+\varepsilon_{i}
\end{aligned}
$$

where $y_{i}$ is our dependent variable measuring the redistributive design of the pension scheme (or the size of pension) in country $i$; COMMUNITARIAN is a dummy variable equal to 1 if country $i$ features a communitarian family and 0 otherwise; AUTHORIT ARI AN is a dummy variable equal to 1 if country $i$ has an authoritarian family and 0 otherwise; $E G A L N U C L E A R$ is a dummy variable equal to 1 if country $i$ has an egalitarian nuclear family and 0 otherwise; $O E C D, L A A M$ and $A F R I C A$ are geographical dummy variables equal to 1 if country $i$ belongs respectively to OECD, Latin America and Africa and 0 otherwise; $X_{i}$ is a set of control variables, which include alternative legal, cultural, political, economic and demographic determinants that could have affected the design and the size of the system, and $\varepsilon_{i}$ is the error term. The absolute nuclear family type is thus the omitted one and our reference family type.

For our dependent variables $y_{i}$ we use different measures of design and size of the pensions: (i) the ratio between the replacement rates of a worker earning one-half of the 
average income and the one of a worker earning exactly the average income (Ratio low); (ii) the ratio between the replacement rate of a worker earning the $75 \%$ of the average income and the one of a worker earning $150 \%$ of the average income (Ratio medium); (iii) the replacement rate of a worker earning the average income (Replace); (iv) the pension coverage, i.e. the share of population between 15 and 64 years old that is covered by the pension system, and (v) the pension spending as a percentage of GDP.

Figures 2 and 3 show the distribution of our main measures of pension design, (ratio low) and (ratio medium) around the world, suggesting that they vary widely across (and within) geographic areas.

Due to the small number of observations, we run different sets of regressions including one of the following control variables, $X$, at a time: legal origins, religion, level of urbanization, level of democracy, GDP and the share of elderly.

Our unit of analysis is the country, since pension design varies at country level but is homogeneous within country. Furthermore, since this design displays a strong time persistence and we have historical data on family types, we abstract from the time component and concentrate on a cross-country analysis. Data availability limits the number of observations to 55 when we use the replacement rates (ratio low) and to 78 when we measure the size of pension. Data sources are described in the appendix. Summary statistics are at table 2 .

\subsection{Results}

Table 3 presents the baseline specification. We regress our measures of the design and size of pensions on the three types of pre-existing family structures and on the geographical dummies. Communitarian and egalitarian nuclear families are less redistributive than absolute nuclear ones according to our two measures of the replacement ratio. Using our most preferred measure ${ }^{13}$ (ratio medium), also authoritarian families are less redistributive than absolute nuclear. This result is in line with the idea that absolute nuclear families feature weak and independent relations between parents and children, which lead to the design of a pension system that resembles a safety net. In families that prize independence, and do not tie the parents' hands to equal inheritance rules, children do not perceive the provision of old-age support to their parents as an obligation, unless perhaps they are in strong need of help. This family organization translates into pension design: individuals

\footnotetext{
${ }^{13}$ This measure considers the ratio of the replacement rates at $75 \%$ and $150 \%$ of the average wage, and thus provides a better picture of the pension design than our other measure that considers the replacement rate of very low income individuals (at $50 \%$ of the average wage).
} 
only expect to receive a safety net from the state. Where instead children took good care of their elderly parents, the state has to provide a sufficient pension to replace the individual previous wage income. This idea is supported by our results. The level of the replacement rate is positively related to the strength of the family ties. All other family types enjoy a higher replacement than countries with absolute nuclear families, indicating that they provide more than just a safety net.

When we turn to the size of pension, as expected, absolute nuclear families are associated with a higher coverage, while current pension spending is instead unrelated to the types of families.

We now enrich our baseline scenario by introducing additional variables to control for alternative channels that may explain the original design of pension systems, or which may influence both pension design and family values. We first introduce legal origins, which, following La Porta et al. (1997) are classified as Anglo-Saxon, Socialist, Germany and French. Figure 4 shows the geographical distribution of these indicators. By comparing figures 1 and 4, we do not see a clear association between family types and legal origins, suggesting that family ties may be capturing some inherent value different from what is expressed by the origin of the legal system. This is confirmed in table 4 , where we add the four dummy variables referring to legal origins in our baseline specification. When compared to communitarian and egalitarian nuclear families, absolute nuclear families remain associated with more Beveridgean schemes and larger coverage. Communitarian families have also a higher replacement rate. Interestingly, Anglo-Saxon legal origins are associated with less coverage and lower pension spending, ${ }^{14}$ but do not seem to affect the design.

We then turn to religion, which has also been considered a crucial and persistent determinant of economic and social outcomes (see section 3.3). We want to control whether religion, rather than the principles underlying family types, is the real driver of the different pension design across countries. The diffusion of the main religions, Catholic, Orthodox, Protestant, Islamic, around the world in 1900 is not directly associated with the design of pensions. Redistributive pensions are present in many Protestant countries, but also in the catholic Argentina and Ireland. In table 5, we control for the relative share of these four religions in the different countries in 1900 (i.e., in the period around or before the introduction of the pension systems). Again, we find that absolute nuclear family are associated with more redistributive pension schemes than other types of families.

\footnotetext{
${ }^{14}$ This result is in line with the idea that private pensions may substitute for public pensions when financial markets are well developed, which is in turn associated with Anglo-Saxon legal origins.
} 
Religion seems to have no effect on pensions design, ${ }^{15}$ but to be associated with low pension expenditure and low coverage, in countries with a large share of Muslims. Similarly, in table 6 , a Herfindal index of religious homogeneity is not significantly associated with the design, while the types of family remain crucial.

In table 7 , we include a measure of the level of urbanization of the country at the beginning of the XX century. While this variable turns out to be associated with the size of the pension systems in the obvious direction (more urbanization implies more pensions), it is not significant to explain the design. The types of family remain instead significant.

In table 8 , we introduce an indicator of the political environment in the different countries in 1900. Do the design of system or their size depend on whether countries were more democratic at the time of the introduction of the system? A higher level of democratization, as captured by the Polity 2 indicator ${ }^{16}$ has no impact on the design of pensions; as usual, having an absolute nuclear family organization implies a significantly different design than any other family type, namely a more redistributive scheme.

In table 9, we control for current economic and demographic variables, that is, the level of GDP and the share of elderly in the population. Richer countries have higher coverage, while more elderly are associated with both higher coverage and more pension spending. ${ }^{17}$ Current income and aging are however not correlated with pension design, and the type of family remains significant in all specifications in the usual way.

Finally, in table 10, we control for electoral rules and forms of government. As expected, countries with majoritarian systems have lower coverage and pension spending, as well as lower replacement rates than countries with proportional systems. However, having a majoritarian or a proportional electoral rule has no impact on the redistributive design of pensions, while family types continue to show the usual effect. The form of government, presidential versus parliamentary, turns out to play no role.

\footnotetext{
${ }^{15}$ Unfortunately, the CIA factbook reports observations only for 49 of the countries for which we have pension data. The coefficient of the family types are less precisely estimated, but point estimates are in line with the estimates in the previous tables.

${ }^{16}$ For details, see the appendix.

${ }^{17}$ There is a large literature on the link between aging and the size of social security (see Galasso and Profeta, 2004, Disney, 2007).
} 


\section{The Individual Data Analysis}

\subsection{Data and empirical specification}

We now turn to individual data to test whether individuals' preferences on the current design of pension system are affected by their family types. We provide two types of evidence.

In the first analysis, we consider individual responses to four questions on the role of the government in providing support to the elderly, contained in different waves of the General Social Survey (GSS) from 1972 to 2008. Following an established literature (see Fernández and Fogli, 2006, 2009, and Alesina and Giuliano, 2007, among many others), we associate to each person the family type of his/her family's country of origin. This information is available since each individual in the GSS is asked to provide his/her birthplace and the country of origin of his/her forbearers - namely to answer to the following question: "From what countries or part of the world did your ancestors come?". We restrict our analysis to the available countries ${ }^{18}$ for which Todd's classification in family types is available.

We concentrate on four questions, which unable us to identify the individual preferences for government responsibility in social issue, and in particular in old age security. First, individuals are asked the following: "We are faced with many problems in this country, none of which can be solved easily or inexpensively. I'm going to name some of these problems, and for each one I'd like you to tell me whether you think we're spending too much money on it, too little money, or about the right amount. Are we spending too much, too little, or about the right amount on social security?" (see social security spending in column 1, table 11, where 1 identifies "too little" and 3 is for "too much"). This question was available in several waves (1983-87, 1987, 1988-91, 1993-96, 1998, 2000, 2002, 2004, 2006, 2008). Second, "On these cards are some opinions about the government and the economy. I'd like you to tell me whether you strongly agree, somewhat agree, somewhat disagree or strongly disagree with the following: It is the responsibility of government to meet everyone's needs, even in case of sickness, poverty, unemployment, and old age." (see government responsibility in column 2, table 11, where 1 means "strongly agree" and 4 "strongly disagree"). This question was only available in the 1983-87 wave. Third, "On

\footnotetext{
${ }^{18}$ The available answers are Africa, Austria, Canada, China, Czechoslovakia, Denmark, England and Wales, Finland, France, Germany, Greece, Hungary, Ireland, Italy, Japan, Mexico, Netherlands, Norway, Philippines, Poland, Puerto Rico, Russia (USSR), Scotland, Spain, Sweden, Switzerland, West Indies, Other to be specified, American Indian, India, Portugal, Lithuania, Yugoslavia, Romania, Belgium, Arabic, Other Spanish, Other Asian, Other European, America. We drop the observations with answers such as Africa, Other Spanish, Other Asian, Other European for which we are unable to match a family type.
} 
the whole, do you think it should or should not be the government's responsibility to provide a decent standard of living for the old?" (see old age spending in column 3, table 11, where 1 is for "it definitely should be" and 4 is for "it definitely should not be"). This question was available for the following waves: 1983-87, 1988-91, 1993-96, 2002, 2006. Forth, "Listed below are various areas of government spending. Please indicate whether you would like to see more or less government spending in retirement benefits. Remember that if you say "much more," it might require a tax increase to pay for it" (see retirement benefit spending in column 4, table 11, where 1 means "you want to spend much more" and 5 is that "you want to spend much less") This question was available for the following waves: 1983-87, 1988-91, 1993-96, 1998, 2006.

For these four questions, we run the following OLS regression:

$y_{i c}=\alpha+\beta_{1} C O M M U N I T A R I A N_{c}+\beta_{2} A U T H O R I T A R I A N_{c}+\beta_{3} E G A L N U C L E A R_{c}+\beta_{4} X_{i}+\varepsilon_{i c}$

where $y_{i c}$ is our dependent variable measuring the response to the above questions by an individual $i$ whose ancestors were coming from country $c$; the dummy refers to the family type in the country of origin of the respondent, and $X_{i}$ is a set of individual controls, such as age, income, level of education and political views, and $\varepsilon_{i c}$ is the error term. Standard errors are clustered at country level. As before, the absolute nuclear family type is the omitted one and our reference family type.

In the second analysis with individual data, we exploit the local (within-country) variation in family ties provided by Todd (1990) to test whether individuals from different family types, but facing the same pension system, have different perceptions on pension policies. In particular, we consider individual responses to a question about pension responsibility included in the 1999 wave of the European Value Survey (EVS), which ranges from "1 - each individual should be responsible for arranging his or her own pension" to "10 - the state should be responsible for everyone's pension". According to Todd (1990), among European countries, different family types coexisted in Finland, France, Italy, Portugal, Spain and the UK. However, among these countries, the EVS question on pension responsibility was only asked in Finland, where communitarian was the dominant family, which coexisted with authoritarian, Portugal, with egalitarian nuclear as dominant and authoritarian in the north of the country, and in the UK, with absolute nuclear being dominant in England and authoritarian in Scotland and other regions.

For each of these three countries, we run the following OLS regression:

$$
y_{i r}=\alpha+\beta_{1} \text { AUTHORITARIAN } N_{r}+\beta_{2} X_{i}+\varepsilon_{i r}
$$

where $y_{i r}$ is our dependent variable measuring the response to the above question by 
an individual $i$ living in region $r$; the dummy Authoritarian refers to the non-dominant family type, which is authoritarian in all countries, and $X_{i}$ is a set of individual controls, such as age, income, level of education and political views, and $\varepsilon_{i r}$ is the error term. Notice that the omitted variable is the dominant family type, and differs by country being communitarian in Finland, egalitarian nuclear in Portugal, and absolute nuclear in the $\mathrm{UK}$.

\subsection{Results}

Consider first the responses to four questions on the role of the government in providing support to the elderly from the 1972-2008 General Social Survey (GSS). Table 11 presents the results of the regression of these individual responses on family type in the respondent's country of origin, and on individual characteristics. US respondents with an egalitarian nuclear family background (i.e., with ancestors coming from countries featuring egalitarian nuclear families) find current US spending in social security to be too low, if compared to people with an absolute nuclear background. Other family backgrounds do not seem to matter. Individual from strong ties families are only weakly more favorable to government responsibility for a variety of individual needs (poverty, sickness, unemployment as well as old age) than people from absolute nuclear families. However, having a strong family background (i.e., ancestors coming from communitarian, egalitarian nuclear and, to a lesser extent, authoritarian countries) matters for explaining individual support ${ }^{19}$ for (i) more government involvement in providing a decent standard of living to the elderly (column 3) and (ii) more government spending in retirement benefits (column 4).

Hence, even when individuals face the same economic and institutional environment, i.e., the same welfare state, after controlling for individual characteristics (such as age, income, education and political orientation), the family culture inherited from the ancestors seems to matter in shaping individual preferences especially when it comes to old age (pension) policies.

Our second analysis on individual date exploits the local difference in family types in Finland, Portugal and the UK. Table 12 reports our regression results. In the UK (column 1), after controlling for individual characteristics, respondents in the regions characterized by an authoritarian family structure (Scotland, Wales, north west and west midlands) are significantly more in favor of state intervention than the individuals living in the remaining regions (England and others), which feature the dominant, weak ties family, i.e., absolute nuclear. In Portugal (column 2), the dominant family structure is egalitarian nuclear, but

\footnotetext{
${ }^{19}$ Multilogit analyses provide similar results.
} 
in the north region authoritarian families are more common. Controlling for individual characteristics, no significant difference emerges between respondents in these two areas. A similar result emerges in Finland, where the dominant family is communitarian, but authoritarian families are relevant in some areas (Pohjanhaa, Uusimaa, and VarsinaisSuomi). Differences in family background have no effect on the respondents' preferences for individual vs. state intervention in old age pensions (column 3).

Evidence obtained using individual data from EVS thus confirm the results of the previous analyses. Even when individuals enjoy the same pension system, after controlling for their individual features, people from weak ties family regions are more likely to prefer individual responsibility for old age pension over state intervention. In this case, the results for the UK suggest that the crucial difference rests in the distance between the independent, absolute nuclear family and the other stronger families, while differences within strong ties families - authoritarian vs. communitarian in Finland, and egalitarian nuclear vs. authoritarian in Portugal - are less relevant.

\section{Conclusions}

We have tried to identified the types of family relationships as the ultimate cause of the design of pension systems. Why family? According to Todd (1983), family ties do not depend on climate conditions, geological features, or economic environment. The system of latent values embedded in the family seems to have no link with religion or language. There is nothing pre-determined to the family relationships. In a world, behind the family there is only the "hazard".

Our empirical analysis shows that family organization was a primal determinant of the pension systems' design since their introduction. Legal origin and religion, which have extensively been suggested to determine other socioeconomic outcomes, had instead no role. Similarly, other features of the political, demographic and economic context in which pensions were introduced, such as the level of urbanization or democratization of the country at that time, or current variables such as current GDP and the share of elderly in the population, have also little power to explain the design of pensions. Interestingly, some of these variables turn out to be related to current features, such as the size or the coverage of the pensions, but not the design. A family organization featuring high independence among individuals, as in absolute nuclear families, is associated with the emergence of a Beveridgean pension system with flat benefit formulas and more redistribution across income levels. Stronger family types, in particular communitarian and egalitarian nuclear, 
match with a Bismarckian (generous) pension schemes. Data on the individual responses to questions on the role of the government in providing support to the elderly provide a similar picture. Using current GSS data, we found that individuals whose ancestors came to the US from countries featuring communitarian or egalitarian nuclear families prefer to rely on the government as a provider of old age security through generous retirement benefits. Moreover, we use individual data from a EVS question on the role of the state in pension policy, to exploit the within-country variation in Todd (1990) classification in family types. Our analysis of the UK suggests that individuals who live in regions featuring weak ties families support individual responsibility for old age pension over state intervention. No difference instead emerge when comparing individuals from different regions all featuring strong ties families, such as authoritarian vs. communitarian in Finland, and egalitarian nuclear vs. authoritarian in Portugal.

Besides having a strong historical component, our analysis may shed some light on the feasibility of today's pension reforms. Individuals' behavior, as shaped by cultural or institutional elements influences the policy-makers' decision on which institution (e.g., pension systems) to choose, how to design it (Bismarckian earnings-related versus Beveridgean flat-rate) and how to implement the policy. This is a promising direction for future research. 


\section{Technical Appendix}

\section{.1 Proof of Proposition 1}

Adults maximize with respect to $\tau_{t}$ the following indirect utility function

$\ln \left[y_{i}\left(1-\tau_{t}\right)-s_{i, t}\right]+\beta \rho \ln \left[\max \left\{\gamma y_{i}, s_{i, t} \bar{R}+P_{i, t+1}\right\}\right]+\beta(1-\rho) \ln \left[\max \left\{\gamma y_{i}, P_{i, t+1}\right\}\right] \quad$ if $s_{i, t} \bar{R}>\gamma y_{i}$

$$
\ln \left[y_{i}\left(1-\tau_{t}\right)-s_{i, t}-\left(1+\phi^{j}\right)\left(\gamma y_{i}-s_{i, t-1} R_{t}-P_{i, t}\right)\right]+
$$

$+\beta \rho \ln \left[\max \left\{\gamma y_{i}, s_{i, t} \bar{R}+P_{i, t+1}\right\}\right]+\beta(1-\rho) \ln \left[\max \left\{\gamma y_{i}, P_{i, t+1}\right\}\right]$ if $s_{i, t} \bar{R}<\gamma y_{i}$

where $P_{i, t}=(1-\varepsilon) \tau_{t} \bar{y}$.

Notice that individuals expect their decisions over $\tau_{t}$ to have no effect on $\tau_{t+1}$, that is, they take $\tau_{t+1}$ and $P_{t+1}$ as given.

For $s_{i, t} \bar{R}>\gamma y_{i}$, we clearly have $\tau_{t}=0$, since a positive tax rate would only represent a cost for the adults.

For $s_{i, t} \bar{R}<\gamma y_{i}$, instead, we have the following first order condition: $F\left(\tau_{t}\right)=-y_{i}+$ $\left(1+\phi^{j}\right)(1-\varepsilon) \bar{y}$. Hence, individuals voting decision will depend on their income:

$$
\tau_{i}=\left\{\begin{array}{lrr}
\frac{\gamma}{1-\varepsilon} \frac{y_{i}}{\bar{y}} & \text { such that } P_{i}=(1-\varepsilon) \tau_{i} \bar{y}=\gamma y_{i} & \text { for } y_{i}<\left(1+\phi^{j}\right)(1-\varepsilon) \bar{y} \\
0 & & \text { for } y_{i}>\left(1+\phi^{j}\right)(1-\varepsilon) \bar{y}
\end{array}\right.
$$

In the old regime, $\phi^{j}=0$, by assumption 1 , we have that $y_{M}>(1-\varepsilon) \bar{y}$, and thus a majority of voters prefer $\tau=0$.

In the new regime, $\phi^{j}=\phi$, high income voters, with $y_{i}>(1+\phi)(1-\varepsilon) \bar{y}=\widetilde{y}$, prefer $\tau=0$, while for the others $\left(y_{i}<\widetilde{y}\right)$ their preferred tax rate is increasing in income. We can thus re-order the individuals' preferences according to their income to have that the median voter, characterized by $y_{M V}$, is such that $F\left(y_{u}\right)-F(\widetilde{y})+F\left(y_{M V}\right)+1 / 2$, with $F\left(y_{u}\right)=1$. The equilibrium tax rate is thus $\tau=\frac{\gamma}{1-\varepsilon} \frac{y_{M V}}{\bar{y}}$.

\section{$.2 \quad$ Proof of proposition 2}

Consider first a Bismarckian pension system, $P_{i, t}=(1-\varepsilon) \tau_{t} y_{i}$. Adults maximize the indirect utility function at eq. 8. Hence, for $s_{i, t} \bar{R}>\gamma y_{i}$, we have $\tau_{t}=0$, while for $s_{i, t} \bar{R}<\gamma y_{i}$ the first order condition becomes: $F\left(\tau_{t}\right)=-1+\left(1+\phi^{j}\right)(1-\varepsilon)$. Hence, for $s_{i, t} \bar{R}<\gamma y_{i}$, in the old regime, $\phi^{j}=0$, all voters oppose pensions, $\tau=0$; in the new regime, 
$\phi^{j}=\phi>0$, according to assumption 2, all voters support a pension system that takes care of the consumption of the elderly, and hence $\tau=\gamma /(1-\varepsilon)$, so that $P_{i}=(1-\varepsilon) \tau y_{i}=\gamma y_{i}$.

Given the results in proposition 1, we can now turn to comparing the two systems.

In the old regime, no pension system is supported $(\tau=0)$, regardless of the design.

In the new regime, for $s_{i, t} R_{t}=0$, individuals with low income, $y_{i} \leq y_{M V}$, prefer the Beveridgean system that provides at least the family consumption to their parents, $P_{i}^{B E V}=\gamma y_{M V} \geq P_{i}^{B I S}=\gamma y_{i}$, at a lower cost, since $\tau_{i}^{B E V}=\frac{\gamma}{1-\varepsilon} \frac{y_{M V}}{\bar{y}}<\tau_{i}^{B I S}=\frac{\gamma}{1-\varepsilon}$, as $y_{M V}<\bar{y}$. For individuals with higher income $\left(y_{i}>y_{M V}\right)$, the Beveridgean pension transfer is not sufficient to cover their parents family consumption level, $P_{i}^{B E V}=\gamma y_{M V}<$ $\gamma y_{i}$. Since they have to top-up the pension benefits with family transfers, the total cost of the Beveridgean system becomes

$$
\tau_{i}^{B E V} y_{i}+(1+\phi)\left(\gamma y_{i}-P_{i}^{B E V}\right)=\frac{\gamma}{1-\varepsilon} \frac{y_{M V}}{\bar{y}} y_{i}+(1+\phi) \gamma\left(y_{i}-y_{M V}\right) .
$$

This cost is smaller than the cost of the Bismarckian system, $\tau^{B I S} y_{i}=\frac{\gamma y_{i}}{1-\varepsilon}$, and thus individuals support a Beveridgean system if $y_{i}<\frac{\widetilde{y}}{\widetilde{y}+y_{M V}-\bar{y}} y_{M V}=\widehat{y}$, and they prefer a Bismarckian system for $y_{i} \geq \widehat{y}$. Hence, for $y_{M} \geq \widehat{y}$ a Bismarckian system emerges with $\tau=\tau^{B I S}$, and a Beveridgean with $\tau=\tau^{B E V}$ for $y_{M}<\widehat{y}$.

Once a system has been introduced for $s_{i, t} R_{t}=0 \forall i$, it will continue to be supported if $s_{i, t} R_{t}=0 \forall i$ also in the future. A sufficient condition for this to occur is that $s_{i, t}=0$ $\forall i$. We now consider the saving decisions. These decisions have a strategic component, as adults realize that, should they arrive in old age with no private wealth, they would receive support from their family. By comparing the lifetime utility associated with no savings,

$$
u_{0}=U_{i}\left(s_{i}=0\right)=\ln \left[y_{i}\left(1-\tau_{t}\right)\right]+\beta \ln \left[\gamma y_{i}\right]
$$

with the utility associated with the optimal savings

$$
u_{s}=U_{i}\left(s_{i}^{*}\right)=\ln \left[y_{i}\left(1-\tau_{t}\right)-s_{i, t}\right]+\beta \rho \ln \left[s_{i, t} \bar{R}\right]+\beta(1-\rho) \ln \left[\gamma y_{i}\right]
$$

where $s_{i}^{*}=\arg \max U_{i}\left(s_{i}\right)=\beta \rho y_{i}\left(1-\tau_{t}\right) /(1+\beta \rho)$, we have that

(i) in a Bismarckian system, i.e., for $\tau_{t}=\tau_{t}^{B I S}=\frac{\gamma}{1-\varepsilon}, u_{0}>u_{s}$ and thus individuals do not save if $\gamma \geq \frac{\beta \rho \bar{R}}{(1+\beta \rho)\left(1+\frac{\rho}{\beta \rho}\right)+\beta \rho \bar{R} /(1-\varepsilon)}$;

(ii) in a Beveridgean system, i.e., for $\tau_{t}=\tau_{t}^{B E V}=\frac{\gamma}{1-\varepsilon} \frac{y_{M V}}{\bar{y}}, u_{0}>u_{s}$ and thus individuals do not save if $\gamma \geq \frac{\beta \rho \bar{R}}{(1+\beta \rho)\left(1+\frac{1}{\beta \rho}\right)+\beta \rho \bar{R} y_{M V} /(1-\varepsilon) \bar{y}}$. 


\section{$.3 \quad$ Proof of proposition 3}

Adults maximize with respect to $\tau_{t}$ the following indirect utility function

$$
\ln \left[y_{i}\left(1-\tau_{t}\right)-s_{i, t}\right]+\beta \rho \ln \left[\max \left\{\delta \bar{y}, s_{i, t} \bar{R}+P_{i, t+1}\right\}\right]+\beta(1-\rho) \ln \left[\max \left\{\delta \bar{y}, P_{i, t+1}\right\}\right] \quad \text { if } s_{i, t} \bar{R}>\delta \bar{y}
$$

$$
\ln \left[y_{i}\left(1-\tau_{t}\right)-s_{i, t}-\left(1+\phi^{j}\right)\left(\delta \bar{y}-s_{i, t-1} R_{t}+P_{i, t}\right)\right]+
$$

$$
+\beta \rho \ln \left[\max \left\{\delta \bar{y}, s_{i, t} \bar{R}+P_{i, t+1}\right\}\right]+\beta(1-\rho) \ln \left[\max \left\{\delta \bar{y}, P_{i, t+1}\right\}\right] \quad \text { if } s_{i, t} \bar{R}<\delta \bar{y}
$$

where $P_{i, t}=(1-\varepsilon) \tau_{t} \bar{y}$ in the Beveridgean system and $P_{i, t}=(1-\varepsilon) \tau_{t} y_{i}$ in the Bismarckian system.

Regardless of the design of the pension system, for $s_{i, t} \bar{R}>\delta \bar{y}$, we have $\tau_{t}=0$.

Consider that $s_{i, t} \bar{R}<\delta \bar{y}$.

In the Bismarckian system, we have the following first order condition: $F\left(\tau_{t}\right)=-1+$ $\left(1+\phi^{j}\right)(1-\varepsilon)$. Hence, in the old regime, $\phi^{j}=0$, all voters oppose pensions, $\tau=0$; while in the new regime, $\phi^{j}=\phi>0$, by assumption 2 , all voters support their most preferred tax rate $\tau_{i}=\frac{\delta \bar{y}}{(1-\varepsilon) y_{i}}$ such that $P_{i}=(1-\varepsilon) \tau y_{i}=\delta \bar{y}$. This tax rate is decreasing in income and the median voter theorem applies.

In the Beveridgean system, we have the following first order condition: $F\left(\tau_{t}\right)=-y_{i}+$ $\left(1+\phi^{j}\right)(1-\varepsilon) \bar{y}$, and thus individuals voting decision will depend on their income:

$$
\tau_{i}=\left\{\begin{array}{lr}
\frac{\delta}{1-\varepsilon} \text { such that } P_{i}=(1-\varepsilon) \tau_{i} \bar{y}=\delta \bar{y} & \text { for } y_{i}<\left(1+\phi^{j}\right)(1-\varepsilon) \bar{y} \\
0 & \text { for } y_{i}>\left(1+\phi^{j}\right)(1-\varepsilon) \bar{y}
\end{array}\right.
$$

In the old regime, $\phi^{j}=0$, by assumption 1 , we have that $y_{M}>(1-\varepsilon) \bar{y}$, and thus a majority of voters prefer $\tau=0$.

In the new regime, $\phi^{j}=\phi$, by assumption 2 , with $y_{M}<(1+\phi)(1-\varepsilon) \bar{y}$, and thus the median voter supports $\tau=\frac{\delta}{1-\varepsilon}$.

Comparing the two systems in the new regime, for $s_{i, t} R_{t}=0$, it is easy to see that individuals with above median income, $y_{i}>y_{M}$, will prefer a Beveridgean system, since both systems cover the elderly parents subsistence consumption level, $P_{i}^{B I S}=\frac{\delta \bar{y} y_{i}}{y_{M}} \geq$ $P_{i}^{B E V}=\delta \bar{y}$, but the Beveridgean system is less costly, since $\tau^{B E V}=\frac{\delta}{1-\varepsilon}<\tau^{B I S}=\frac{\delta}{1-\varepsilon} \frac{\bar{y}}{y_{M}}$ with $y_{M}<\bar{y}$. Below median income individuals, $y_{i}<y_{M}$, have to top-up the pension benefits with private transfers, in the Bismarckian system, so its cost to the adults is

$$
\tau_{i}^{B I S} y_{i}+(1+\phi)\left(\delta \bar{y}-P_{i}^{B I S}\right)=\frac{\delta \bar{y}}{1-\varepsilon} \frac{y_{i}}{y_{M}}+(1+\phi) \delta \bar{y}\left(1-\frac{y_{i}}{y_{M}}\right)
$$


This is clearly larger than the cost of a Beveridgean system, $\tau^{B E V} y_{i}=\frac{\delta}{1-\varepsilon} y_{i}$ for low income adults with $y_{i}<y_{M}$. Hence, all individuals support a Beveridgean system when $s_{i, t} R_{t}=0$.

Once a Beveridgean system has been introduced for $s_{i, t} R_{t}=0 \forall i$, it will continue to be supported if $s_{i, t} R_{t}=0$ for a majority of the adults also in the future. A sufficient condition for this to occur is that $s_{i, t}=0 \forall i$. We now consider the saving decisions. These decisions have a strategic component, as adults realize that, should they arrive in old age with no private wealth, they would receive support from their family. By comparing the lifetime utility associated with no savings,

$$
u_{0}=U_{i}\left(s_{i}=0\right)=\ln \left[y_{i}\left(1-\tau_{t}\right)\right]+\beta \ln [\delta \bar{y}]
$$

with the utility associated with the optimal savings

$$
u_{s}=U_{i}\left(s_{i}^{*}\right)=\ln \left[y_{i}\left(1-\tau_{t}\right)-s_{i, t}\right]+\beta \rho \ln \left[s_{i, t} \bar{R}\right]+\beta(1-\rho) \ln [\delta \bar{y}]
$$

where $s_{i}^{*}=\arg \max U_{i}\left(s_{i}\right)$, we have that in a Beveridgean system, i.e., for $\tau_{t}=\tau_{t}^{B E V}=$ $\frac{\delta}{1-\varepsilon}, u_{0}<u_{s}$ and thus $s_{i}^{*}>0$ for $y_{i}>y_{S}=\frac{\delta \bar{y}(1+\beta \rho)\left(1+\frac{1}{\beta \rho}\right)}{\beta \rho \bar{R}\left(1-\frac{\delta}{1-\varepsilon}\right)}$.

Hence, if $y_{M}<y_{S}, s_{i}^{*}=0$ for a majority of the adults, and a Beveridgean system is always supported. If $y_{M}>y_{S}$, and hence $s_{i}^{*}>0$ for a majority of the adults, when $R=\bar{R}$, the system is not supported and $\tau=0$.

\section{A Data appendix}

We here describe the variables used in the empirical analysis and their sources.

- Replacement rates of the pension system at 50\%,75\%,100\% and $150 \%$ of average labor income are built on Whitehouse (2007) "Pension Panorama" The World Bank and OECD (2009) "Pension at a Glance. Special Edition: Asia/Pacific. From these data we calculate Ratio low: the ratio between the replacement rate of a worker earning one-half of the average income and the one of a worker earning exactly the average income; Ratio medium: the ratio between the replacement rate of a worker earning the $75 \%$ of the average income and the one of a worker earning $150 \%$ of the average income; and replace: the replacement rate of a worker earning the average income. Data on ratio medium are available for the following countries: Algeria, Argentina, Australia, Austria, Bahrain, Belgium, Bulgaria, Canada, Chile, Colombia, Costa Rica, Croatia, Czech Republic, Denmark, Dominican Republic, Egypt, El Salvador, Estonia, Finland, France, Germany, Greece, Hungary 
, Iran, Ireland, Italy, Japan, Jordan, Latvia, Libya, Lithuania, Luxembourg, Mexico, Morocco, Netherlands, New Zealand, Norway, Peru, Poland, Portugal, Slovak Republic, South Korea, Spain, Sweden, Tunisia, Turkey, United Kingdom, United States, Uruguay, Yemen. Data on replace and ration low include also China, India, Indonesia, Pakistan, Vietnam.

- Coverage is the share of population between 15 and 64 years old that is covered by the pension system. It is constructed as the mean of different observations over time. Source: World Bank (2007). HDNSP pension database. With respect to the previous variable, the sample includes some additional countries, Afghanistan, Albania, Bangladesh, Bolivia, Brazil, Dominica, Ecuador, Jamaica, Kazakhstan, Kyrgyzstan, Lebanon, Nicaragua, Paraguay, Syria, Venezuela, Yugoslavia, but excludes Bulgaria, Dominican Republic, New Zealand.

- Pension spending: this variable indicates how much pensions count as a share of GDP. The data were collected in different time periods, in particular between 1991 and 2006. However most of them come from a period around the 2000. Source: World Bank (2007), HDNSP pension database. The sample includes the same countries as coverage 1564 with the addition of Azerbaijan, Belize, Cuba, Dominican Republic, Ethiopia, Guatemala, Honduras, Israel, Kuwait, New Zealand, Panama, Russia, Slovenia, Trinidad \& Tobago, Turkmenistan, Uzbekistan and the exclusion of Bahrain, Dominica, India, Indonesia, Kazakhstan, South Korea.

- Family types variables:

- AbsoluteEgal: this variable is equal to one if the family is absolute nuclear and zero otherwise. Source: Todd (1983).

- Communitarian: this variable is equal to one if the family is communitarian and zero otherwise. Source: Todd (1983).

- Authoritarian: this variable is equal to zero if there are authoritarian families and zero otherwise. Source: Todd (1983).

- Egalit Nuclear: this variable is equal to zero if there are egalitarian nuclear families and zero otherwise. Source: Todd (1983).

- Legal origins variables: the origin of the legal system in a country is indicated by a set of dummy variables Legal Eng, Legal Socialist, Legal German, Legal French. Each dummy is equal to one if the country has the particular legal origin of interest and 
zero otherwise. In general we do not have overlapping among the dummies. More precisely: Legal Eng refers to an Anglo-Saxon legal origin; Legal Socialist refers to a socialist legal origin; Legal German to a Germany legal origin; Legal French to a French legal origin. Source: La Porta et al. (1998).

- Religion variables:

- Catholic 1900, Orthodox 1900, Protestant 1900, Muslim 1900 contain the percentage in 1900 over the entire population of Catholic, Orthodox, Protestant and Muslin people respectively. Source: CIA factbook.

- Herfrel1900: this variable is a proxy for the level of religious heterogeneity is a country in 1900. It has been constructed computing the Hirschman-Herfindahl index using the religion data. In particular we have data on the following religions: catholic, protestant, orthodox, Muslim, Jewish, Buddhism, East Religions;

- Urban: this variable contains the share of population living in an urban area in the early XX century. Source: World Bank, World Development Indicators (WDI).

- Polity2_1900: This data presents an evaluation of the political situation in the different countries. The ranking goes from -10 (hereditary monarchy) to +10 (consolidated democracy). The score is computed by subtracting the AUTOC score from the DEMOC score, where these indicators are derived from coding of the competitiveness of political participation, the openness and competitiveness of executive recruitment and constraints on the chief executive using different weights. Source: Center of Systemic peace, the Policy IV Project (http://www.systemicpeace.org/polity/polity4.htm). Data refers to the year 1900.

- Ln GPDpc: logarithm of the GDP per capita in the 2000. Source: World Bank, World Development Indicators

- Share of Elderly: share of people older than 65 years old over the entire population in 2000. Source: World Bank, World Development Indicators

- Electoral Rules: the dummy variable Majoritarian takes value one if the country has a majoritarian system and zero otherwise (proportional or mixed). Source: Persson and Tabellini (2004)

- Form of Government: the dummy variable Presidential takes value one if the country has a presidential regime and zero otherwise (parliamentary). Source: Persson and Tabellini (2004) 
- Geographic dummy variables:

- Oecd: dummy variable equal to one if the country of interest is an OECD country and zero otherwise;

- Laam: dummy variable that is equal to one if the country of interest is a Latin America country and zero otherwise;

- Africa: dummy variable that is equal to one if the country of interest is an African country and zero otherwise; 


\section{References}

[1] Acemoglu, D., Johnson, S. and Robinson, J.A. (2001) "The colonial origins of comparative development: An empirical investigation", American Economic Review 91(5):1369-1401.

[2] Acemoglu, D. and J. A. Robinson (2006) "Economic Origins of Dictatorship and Democracy", New York: Cambridge University Press.

[3] Alesina, A. and P. Giuliano (2010) "The Power of the Family", Journal of Economic Growth 15: 93-125.

[4] Alesina, A., Algan, Y., Cahuc, P. and Giuliano, P. (2010) "Family values and the regulation of labor", NBER Working Paper No. 15747.

[5] Algan, Y. and Cahuc, P. (2007) "The roots of low european employment: Family culture?", NBER Macroeconomic Annual, MIT Press eds J. Frenkel and C. Pissarides.

[6] Banfield, E.C. (1958) "The moral basis of a backward society" Glencoe, III Free Press.

[7] Boix, C. (2003) "Democracy and Redistribution", New York: Cambridge University Press.

[8] Caucutt, E., T. F. Cooley and N. Guner (2007) "The Farm, the City, and the Emergence of Social Security," NBER Working Paper No. 12854.

[9] Coleman, J.S. (1988) "Social capital in the creation of human capital", American Journal of Sociology (XCIV): S95-S120.

[10] Coleman, J.S. (1990) "Foundations of social theory", Harvard University Press.

[11] Conde Ruiz, J.I. and Profeta, P. (2007) "The Redistributive Design of Social Security Systems", The Economic Journal 117 (April), 686-712.

[12] Cutler, D., Gruber, J., (1996) "Does public insurance crowd out private insurance?", Quarterly Journal of Economics 111 (2), 391-430.

[13] Cutler, D. M., and R. Johnson (2004) "The Birth and Growth of the Social Insurance State: Explaining Old Age and Medical Insurance across Countries," Public Choice 120, pp. 87-121.

[14] Daly, M. (1997) "Welfare states under pressure: cash benefits in European welfare states over the last ten years" Journal of European Social Policy 7(2):129-146. 
[15] Disney, R. and Johnson, P. ed. (2001) "Pension Systems and Retirement Incomes across OECD countries", Edward Elgar editor.

[16] Disney, R. (2007). "Population ageing and the size of the welfare state: Is there a puzzle to explain?", European Journal of Political Economy 23(2), 542-553.

[17] Duranton, G., Rodriguez Pose, A. and Sandall, R. (2009) "Family Types and the Persistence of Regional Disparities in Europe", Economic Geography 85(1): 23-47.

[18] Esping-Andersen, G. (1999) "Social foundations of postindustrial economies", Oxford Economic Press.

[19] Fernández, R. (2007), "Culture and Economics" in The New Palgrave Dictionary of Economics, 2nd Edition

[20] Fernández, R. and Fogli, A. (2009) "Culture: An empirical investigation of beliefs, work and fertility", American Economic Journal: Macroeconomics, 1,1: 146-177.

[21] Flora, P. (1983) "State, Economy and Society in Western Europe 1815-1975.", A data Handbook in two Volumes, London, Macmillan Press.

[22] Flora, P. (ed.) (1987) "Growth to Limits: The Western European Welfare States since World War II" .Volume I and II, Walter De Gruyter.

[23] Galasso, V. (2006), "The Political Future of Social Security in Aging Societies",. Cambridge, MA: MIT Press.

[24] Galasso, V. and Profeta, P. (2004) "Lessons for an Aging Society: the Political Sustainability of Social Security Systems", Economic Policy: 63-115.

[25] Galasso, V. Gatti, R. and Profeta, P. (2009) "Investing for the old age: Pensions, children and savings", International Tax and Public Finance 16(4): 538-559.

[26] Goody, J. (2000) "The european family: an historico-anthropological essay", Blackwell.

[27] Guiso, L., Sapienza, P. and Zingales, L. (2003) "People's opium? Religion and economic attitudes", Journal of Monetary Economics 50:225-282.

[28] Guiso, L., Sapienza, P. and Zingales, L. (2006) "Does culture affect economic outcomes", Journal of Economic Perspectives, 20(2):23-48. 
[29] Greif, A. (2006), "Institutions and the path to the modern economy: Lessons from medieval trade", Cambridge University Press.

[30] van Kersberger, K. and Manow, P. (2009) "Religion, class coalitions and welfare states", Cambridge University Press.

[31] Koethenburger, M., Poutvaara, P. and Profeta, P. (2008), "Why are more redistributive social security systems smaller?" Oxford Economic Papers 60(2): 275-292.

[32] Krieger, T. and Traub, S. (2008), "Back to Bismarck? Shifting preferences for intragenerational redistribution in OECD pension systems", Center for International Economics W.P. Series 13.

[33] La Porta, Rafael, Florencio Lopez-de-Silanes, Andrei Shleifer and Robert Vishny (1997), "Legal Determinants of External Finance", Journal of Finance 52 (3), 11311150.

[34] Lewis, J.(1992). "Gender and the development of welfare regimes", Journal of European Social Policy 2(3), 159-173.

[35] Licht, A., Goldschmidt, C. and Scwartz, S.H.(2007) "Culture rules: The foudnations of the rule of law and other norms of governance", Journal of Comparative Economics (35): 659-688.

[36] Lindert, Peter H. (1994) "The Rise of Social Spending, 1880-1930", Explorations in Economic History 31, 1-37.

[37] Lipset, S. M. (1959) "Some Social Prerequisites for Democracy: Economic Development and Political Legitimacy", American Political Science Review, 53, 69-105.

[38] McCleary, R. and Barro, R. (2006) "Religion and Economy", Journal of Economic Perspectives 20(2):49-72.

[39] Mulligan, C. B., R. Gil, and X. Sala-i-Martin (2010). "Social Security and Democracy," The B.E. Journal of Economic Analysis \& Policy, Berkeley Electronic Press, vol. 10(1).

[40] North, D.C. (1990) "Institutions, institutional change and economic performance", Cambridge University Press.

[41] OECD (2005). "Pensions at a Glance. Public policies across OECD countries" OECD. 
[42] OECD (2009) "Pension at a Glance". Special Edition: Asia/Pacific, OECD.

[43] Perotti, E., and A. Schwienbacker (2008) "The Political Origin of Pension Funding", Journal of Financial Intermediation 18: 384-404.

[44] Persson, T. and Tabellini, G. (2004) "The economic effects of constitutions", MIT Press.

[45] Pfau-Effinger, B. (2005) "Culture and welfare state policies: Reflections on a complex interrelation" Journal of Social Policy 34, 1:3-20.

[46] Pinotti, P. (2009) "Financial Development and Pay-As-You-Go Social Security" Topics in Macroeconomics, Berkeley Electronic Press, vol. 9(1): 1674-1674

[47] Putnam, R. (1993) "Making democracy work". Princeton, NJ: Princeton University Press.

[48] Reher, D. S. (1998) "Family ties in western Europe: Persistent contrasts", Population and Development Review, 24(2), 203-234.

[49] Smith, D. (1996) "Charity, self-interest and welfare: reflections from demographic and family history" in Charity, self-interest and welfare in the English past, ed. by M.Daunton, London UCL Press.

[50] Tabellini, G. (2008) "Institutions and culture", Journal of the European Economic Association Papers and Proceedings, Vol.6(2-3): 255-294.

[51] Tabellini, G. (2009) "Culture and institutions: Economic development in the regions of Europe". Journal of the European Economic Association, forthcoming.

[52] Todd, E. (1983) "La troisième planète", Paris: Seuil.

[53] Todd, E. (1990) "L’invention de l'Europe". Paris: Seuil.

[54] Twigg, J. and Grand, A. (1998) "Contrasting legal conceptions of family obligation and financial reciprocity in the support of older people: France and England", Ageing and Society 18:131-146.

[55] Weber, M. (1905) "The protestant ethic and the spirit of capitalism", London:Allen \& Unwin.

[56] Whitehouse (2007) "Pension Panorama", World Bank. 
Table 1: Family ties and family types

\begin{tabular}{|c|c|c|c|}
\hline VARIABLES & $\begin{array}{c}(1) \\
\text { Family } \\
\text { importance }\end{array}$ & $\begin{array}{c}\text { (2) } \\
\text { Parental } \\
\text { Respect } \\
\end{array}$ & $\begin{array}{c}\text { (3) } \\
\text { Parental } \\
\text { Responsibility }\end{array}$ \\
\hline age & $\begin{array}{c}-0.007 * * * \\
(0.001)\end{array}$ & $\begin{array}{c}-0.001 \\
(0.001)\end{array}$ & $\begin{array}{c}-0.004 * * * \\
(0.001)\end{array}$ \\
\hline Age squared & $\begin{array}{c}7.74 \mathrm{e}-05 * * * \\
(1.24 \mathrm{e}-05)\end{array}$ & $\begin{array}{l}-2.91 \mathrm{e}-06 \\
(1.06 \mathrm{e}-05)\end{array}$ & $\begin{array}{c}2.74 \mathrm{e}-05^{* * *} \\
(1.00 \mathrm{e}-05)\end{array}$ \\
\hline Income & $\begin{array}{c}-0.009 * * * \\
(0.002)\end{array}$ & $\begin{array}{c}0.006^{* * *} \\
(0.002)\end{array}$ & $\begin{array}{l}0.0008 \\
(0.003)\end{array}$ \\
\hline Education & $\begin{array}{c}0.004 \\
(0.002)\end{array}$ & $\begin{array}{c}0.009 * * * \\
(0.002)\end{array}$ & $\begin{array}{c}0.015^{* * *} \\
(0.003)\end{array}$ \\
\hline Political orientation & $\begin{array}{c}0.003 \\
(0.004)\end{array}$ & $\begin{array}{c}0.015^{* * *} \\
(0.003)\end{array}$ & $\begin{array}{c}0.008 * * \\
(0.003)\end{array}$ \\
\hline Communitarian & $\begin{array}{c}0.039 \\
(0.040)\end{array}$ & $\begin{array}{c}-0.135 * * \\
(0.065)\end{array}$ & $\begin{array}{c}0.086 * * * \\
(0.031)\end{array}$ \\
\hline Autoritarian & $\begin{array}{c}0.019 \\
(0.033)\end{array}$ & $\begin{array}{c}0.012 \\
(0.088)\end{array}$ & $\begin{array}{c}0.163^{* * *} \\
(0.049)\end{array}$ \\
\hline Egalit Nuclear & $\begin{array}{c}0.018 \\
(0.035)\end{array}$ & $\begin{array}{c}-0.142 * * \\
(0.065)\end{array}$ & $\begin{array}{c}0.014 \\
(0.025)\end{array}$ \\
\hline Constant & $\begin{array}{c}1.259 * * * \\
(0.041)\end{array}$ & $\begin{array}{c}0.219 * * * \\
(0.064)\end{array}$ & $\begin{array}{c}0.180 * * * \\
(0.039)\end{array}$ \\
\hline $\begin{array}{l}\text { Observations } \\
\text { R-squared }\end{array}$ & $\begin{array}{c}101169 \\
0.007\end{array}$ & $\begin{array}{c}94631 \\
0.037\end{array}$ & $\begin{array}{c}89011 \\
0.028\end{array}$ \\
\hline
\end{tabular}

Robust standard errors in parentheses

$$
\text { *** } \mathrm{p}<0.01,{ }^{* *} \mathrm{p}<0.05,{ }^{*} \mathrm{p}<0.1
$$


Table 2: Summary statistics

\begin{tabular}{llllll}
\hline Variable & Obs & Mean & Std. Dev. & Min & Max \\
\hline Ratio Low & & & & & \\
Ratio Medium & 55 & 1.231257 & .304288 & .8593314 & 2 \\
Replacement & 50 & 1.165635 & .2707104 & .8409091 & 2 \\
Coverage & 55 & 71.79455 & 23.16048 & 16.2 & 125.4 \\
Pension Spending & 68 & 39.44265 & 24.83791 & 2.1 & 95.5 \\
\hline & 78 & 6.070513 & 4.554607 & 0 & 15 \\
Communitarian & & & & & \\
Autoritarian & 78 & .4358974 & .4990834 & 0 & 1 \\
Egalitarian nuclear & 78 & .1282051 & .336482 & 0 & 1 \\
Absolut nuclear & 78 & .3461538 & .4788222 & 0 & 1 \\
\hline & 78 & .0897436 & .287664 & 0 & 1 \\
Legal English & & & & & \\
Legal Socialist & 78 & 1410256 & .3503008 & 0 & 1 \\
Legal French & 78 & .2564103 & .4394772 & 0 & 1 \\
Legal German & 78 & .5128205 & .5128205 & 0 & 1 \\
Catholic in 1900 & 78 & .0384615 & .1935524 & 0 & 1 \\
Protestant in 1900 & 49 & .4662041 & .4243819 & 0 & .992 \\
Orthodox in 1900 & 49 & .2058776 & .3351906 & 0 & .839 \\
Muslisms 1900 & 49 & .0683224 & .1434626 & 0 & .997 \\
Herfindrel Index in 1900 & 49 & .189102 & .3724387 & 0 & 1 \\
Urban & 49 & .7779092 & .1950197 & .338706 & 97000 \\
polity2 in 1900 & 73 & 63921.92 & 19240.71 & 15400 & 10 \\
Elderly population in 2005 & 45 & -.2666667 & 6.213621 & -10 & 19.9696 \\
Ln GDP per capita & 76 & 9.67852 & 5.369072 & 1.768561 & 1 \\
Majoritarian & 75 & 8.15069 & 1.407489 & 4.706893 & \\
Presidential & 52 & .2115385 & .4123837 & 0 & .4798 \\
\hline & 52 & .3846154 & .4912508 & 0 & \\
\hline
\end{tabular}


Table 3: Baseline specification

\begin{tabular}{|c|c|c|c|c|c|}
\hline & RATIO & RATIO & REPLACE & COVERAGE & PENSION \\
\hline VARIABLES & LOW & MEDIUM & & & SPENDING \\
\hline \multirow[t]{2}{*}{ Communitarian } & $-0.47 * * *$ & $-0.51 * * *$ & $29.54 * * *$ & $-31.96 * * *$ & 0.74 \\
\hline & $(0.15)$ & $(0.12)$ & (10.45) & (8.56) & (2.26) \\
\hline \multirow[t]{2}{*}{ Autoritarian } & -0.21 & $-0.23 *$ & 12.81 & -1.22 & 1.81 \\
\hline & $(0.14)$ & $(0.13)$ & (8.51) & (3.45) & (1.44) \\
\hline \multirow[t]{2}{*}{ Egalit Nuclear } & $-0.35 * *$ & $-0.46 * * *$ & $28.50 * * *$ & $-8.20 * * *$ & 2.37 \\
\hline & $(0.16)$ & (0.11) & (7.28) & (2.60) & (1.84) \\
\hline \multirow[t]{2}{*}{ oecd } & -0.05 & -0.05 & 10.17 & $13.18^{*}$ & $4.17 * *$ \\
\hline & (0.09) & $(0.05)$ & (9.13) & (7.78) & (2.04) \\
\hline \multirow[t]{2}{*}{ laam } & 0.20 & 0.17 & -8.53 & $-27.69 * * *$ & -3.11 \\
\hline & $(0.17)$ & $(0.11)$ & $(12.97)$ & (7.11) & (3.14) \\
\hline \multirow[t]{2}{*}{ africa } & $-0.10 * *$ & -0.00 & 14.89 & -1.35 & $-2.71 * *$ \\
\hline & $(0.04)$ & $(0.03)$ & (10.05) & (5.78) & (1.08) \\
\hline \multirow[t]{2}{*}{ Constant } & $1.56 * * *$ & $1.52 * * *$ & $44.94 * * *$ & $58.53 * * *$ & $4.45^{*}$ \\
\hline & $(0.15)$ & $(0.12)$ & (10.53) & $(7.82)$ & $(2.31)$ \\
\hline Observations & 55 & 50 & 55 & 68 & 78 \\
\hline R-squared & 0.314 & 0.378 & 0.185 & 0.661 & 0.360 \\
\hline
\end{tabular}

Robust standard errors in parentheses *** $\mathrm{p}<0.01,{ }^{* *} \mathrm{p}<0.05,{ }^{*} \mathrm{p}<0.1$ 
Table 4: Legal Origin

\begin{tabular}{|c|c|c|c|c|c|}
\hline & RATIO & RATIO & REPLACE & COVERAGE & PENSION \\
\hline VARIABLES & LOW & MEDIUM & & & SPENDING \\
\hline \multirow[t]{2}{*}{ Communitarian } & $-0.35^{*}$ & $-0.38 * *$ & $17.43^{*}$ & $-36.96 * * *$ & -3.09 \\
\hline & $(0.18)$ & $(0.16)$ & (10.12) & (7.91) & (2.13) \\
\hline \multirow[t]{2}{*}{ Autoritarian } & -0.01 & -0.03 & 3.13 & -7.16 & -1.03 \\
\hline & $(0.16)$ & $(0.15)$ & (9.23) & (8.07) & (1.52) \\
\hline \multirow[t]{2}{*}{ Egalit Nuclear } & -0.14 & $-0.28 *$ & 9.86 & $-10.13^{*}$ & 0.33 \\
\hline & (0.19) & (0.16) & (11.44) & (5.27) & (1.75) \\
\hline \multirow[t]{2}{*}{ Legal Eng } & 0.08 & 0.19 & -10.69 & $-16.87 * *$ & $-5.18 * * *$ \\
\hline & $(0.16)$ & $(0.16)$ & (8.11) & (7.91) & (1.38) \\
\hline \multirow[t]{2}{*}{ Legal Socialist } & -0.19 & 0.024 & -0.89 & 7.02 & 1.66 \\
\hline & $(0.14)$ & $(0.14)$ & (9.83) & $(10.45)$ & $(1.91)$ \\
\hline \multirow[t]{2}{*}{ Legal German } & $-0.33^{*}$ & -0.21 & 4.56 & -8.34 & 0.61 \\
\hline & $(0.17)$ & $(0.16)$ & $(10.84)$ & $(6.57)$ & (1.80) \\
\hline \multirow[t]{2}{*}{ Legal Franch } & -0.19 & -0.06 & 14.87 & -14.46 & $-2.50 * *$ \\
\hline & $(0.12)$ & $(0.12)$ & (10.38) & (8.99) & $(1.24)$ \\
\hline \multirow[t]{2}{*}{ Constant } & $1.58 * * *$ & $1.39 * * *$ & $55.74^{* * *}$ & $67.09 * * *$ & $8.31^{* *}$ \\
\hline & $(0.24)$ & $(0.21)$ & $(16.10)$ & (10.54) & (3.16) \\
\hline Regional Dummy & Yes & Yes & Yes & Yes & Yes \\
\hline Observations & 55 & 50 & 55 & 68 & 78 \\
\hline R-squared & 0.410 & 0.465 & 0.274 & 0.759 & 0.529 \\
\hline
\end{tabular}

Robust standard errors in parentheses *** $\mathrm{p}<0.01,{ }^{* *} \mathrm{p}<0.05,{ }^{*} \mathrm{p}<0.1$ 
Table 5: Religion

\begin{tabular}{|c|c|c|c|c|c|}
\hline VARIABLES & $\begin{array}{l}\text { RATIO } \\
\text { LOW }\end{array}$ & $\begin{array}{l}\text { RATIO } \\
\text { MEDIUM }\end{array}$ & REPLACE & COVERAGE & $\begin{array}{l}\text { PENSION } \\
\text { SPENDING }\end{array}$ \\
\hline Communitarian & $\begin{array}{c}-0.44 * * * \\
(0.15)\end{array}$ & $\begin{array}{c}-0.52 * * * \\
(0.14)\end{array}$ & $\begin{array}{c}21.36 * * \\
(9.76)\end{array}$ & $\begin{array}{l}-7.96 * \\
(4.63)\end{array}$ & $\begin{array}{c}1.49 \\
(1.68)\end{array}$ \\
\hline Autoritarian & $\begin{array}{l}-0.23 \\
(0.17)\end{array}$ & $\begin{array}{l}-0.27^{*} \\
(0.16)\end{array}$ & $\begin{array}{l}13.34 \\
(8.38)\end{array}$ & $\begin{array}{c}1.29 \\
(3.11)\end{array}$ & $\begin{array}{c}2.48 \\
(1.54)\end{array}$ \\
\hline Egalit Nuclear & $\begin{array}{l}-0.30 \\
(0.18)\end{array}$ & $\begin{array}{c}-0.51 * * * \\
(0.15)\end{array}$ & $\begin{array}{c}25.55^{* *} \\
(10.06)\end{array}$ & $\begin{array}{l}-4.18 \\
(4.16)\end{array}$ & $\begin{array}{c}6.07 * * * \\
(1.81)\end{array}$ \\
\hline Catholic 1900 & $\begin{array}{l}-0.08 \\
(0.18)\end{array}$ & $\begin{array}{l}-0.00 \\
(0.14)\end{array}$ & $\begin{array}{c}4.545 \\
(19.39)\end{array}$ & $\begin{array}{l}-0.02 \\
(9.67)\end{array}$ & $\begin{array}{l}-3.22 \\
(5.29)\end{array}$ \\
\hline protestant 1900 & $\begin{array}{l}-0.03 \\
(0.17)\end{array}$ & $\begin{array}{l}-0.08 \\
(0.13)\end{array}$ & $\begin{array}{c}3.023 \\
(14.39)\end{array}$ & $\begin{array}{c}7.06 \\
(7.98)\end{array}$ & $\begin{array}{l}-0.56 \\
(4.87)\end{array}$ \\
\hline Orthodox 1900 & $\begin{array}{l}-0.35 \\
(0.25)\end{array}$ & $\begin{array}{l}-0.01 \\
(0.20)\end{array}$ & $\begin{array}{c}13.50 \\
(23.51)\end{array}$ & $\begin{array}{c}5.18 \\
(11.43)\end{array}$ & $\begin{array}{l}-4.11 \\
(5.75)\end{array}$ \\
\hline Muslim 1900 & $\begin{array}{l}-0.08 \\
(0.17)\end{array}$ & $\begin{array}{l}-0.05 \\
(0.13)\end{array}$ & $\begin{array}{c}31.85 \\
(20.44)\end{array}$ & $\begin{array}{c}-38.94^{* * *} \\
(10.11)\end{array}$ & $\begin{array}{l}-9.19 * \\
(5.18)\end{array}$ \\
\hline Constant & $\begin{array}{c}1.60^{* * *} \\
(0.20)\end{array}$ & $\begin{array}{c}1.57^{* * * *} \\
(0.16)\end{array}$ & $\begin{array}{c}45.09 * * * \\
(16.55)\end{array}$ & $\begin{array}{c}60.75^{* * *} \\
(8.26)\end{array}$ & $\begin{array}{l}9.57 * \\
(5.19)\end{array}$ \\
\hline Regional Dummies & Yes & Yes & Yes & Yes & Yes \\
\hline Observations & 49 & 49 & 49 & 47 & 47 \\
\hline R-squared & 0.355 & 0.379 & 0.332 & 0.862 & 0.637 \\
\hline
\end{tabular}

Robust standard errors in parentheses *** $\mathrm{p}<0.01,{ }^{* *} \mathrm{p}<0.05,{ }^{*} \mathrm{p}<0.1$ 
Table 6: Religious Homogeneity

\begin{tabular}{|c|c|c|c|c|c|}
\hline & RATIO & RATIO & REPLACE & COVERAGE & PENSION \\
\hline VARIABLES & LOW & MEDIUM & & & SPENDING \\
\hline \multirow[t]{2}{*}{ Communitarian } & $-0.58 * * *$ & $-0.54 * * *$ & $34.76 * * *$ & $-20.71 *$ & -0.715 \\
\hline & $(0.14)$ & $(0.12)$ & (10.75) & (11.71) & (2.38) \\
\hline \multirow[t]{2}{*}{ Autoritarian } & $-0.31 * *$ & $-0.26 *$ & 13.42 & 2.79 & 3.12 \\
\hline & $(0.14)$ & $(0.14)$ & (9.662) & (6.13) & (2.07) \\
\hline \multirow[t]{2}{*}{ Egalit Nuclear } & $-0.47 * * *$ & $-0.49 * * *$ & $29.09 * * *$ & -3.58 & $5.55 * * *$ \\
\hline & $(0.15)$ & (0.11) & (9.57) & (6.28) & (1.98) \\
\hline \multirow[t]{2}{*}{ herfrel1900 } & $0.37 *$ & 0.10 & -3.67 & -17.92 & -4.88 \\
\hline & $(0.18)$ & $(0.15)$ & $(20.11)$ & (14.03) & (3.65) \\
\hline \multirow[t]{2}{*}{ Constant } & $1.37 * * *$ & $1.48 * * *$ & $49.93 * * *$ & $72.88 * * *$ & $10.46 * * *$ \\
\hline & $(0.17)$ & $(0.14)$ & (14.02) & (10.21) & (2.95) \\
\hline Regional Dummy & Yes & Yes & Yes & Yes & Yes \\
\hline Observations & 49 & 49 & 49 & 47 & 47 \\
\hline R-squared & 0.381 & 0.378 & 0.252 & 0.684 & 0.534 \\
\hline
\end{tabular}

Robust standard errors in parentheses $* * * \mathrm{p}<0.01,{ }^{* *} \mathrm{p}<0.05,{ }^{*} \mathrm{p}<0.1$ 
Table 7: Urban

\begin{tabular}{|c|c|c|c|c|c|}
\hline & RATIO & RATIO & REPLACE & COVERAGE & PENSION \\
\hline VARIABLES & LOW & MEDIUM & & & SPENDING \\
\hline \multirow[t]{2}{*}{ Communitarian } & $-0.54 * * *$ & $-0.53 * * *$ & $35.11 * * *$ & $-19.13^{*}$ & 1.13 \\
\hline & $(0.15)$ & $(0.13)$ & (10.79) & (10.26) & (1.80) \\
\hline \multirow[t]{2}{*}{ Autoritarian } & -0.23 & $-0.24 *$ & 13.95 & 0.87 & 1.95 \\
\hline & $(0.14)$ & $(0.13)$ & (8.367) & $(4.00)$ & (1.35) \\
\hline \multirow[t]{2}{*}{ Egalit Nuclear } & $-0.41 * *$ & $-0.48 * * *$ & $32.40 * * *$ & -0.49 & $5.49 * * *$ \\
\hline & $(0.16)$ & $(0.12)$ & (8.41) & $(4.15)$ & (1.51) \\
\hline \multirow[t]{2}{*}{ Urban } & $-3.24 \mathrm{e}-06$ & $-1.30 e-06$ & 0.00 & $0.00 * * *$ & $9.14 \mathrm{e}-05^{* * *}$ \\
\hline & $(2.39 \mathrm{e}-06)$ & $(2.54 \mathrm{e}-06)$ & $(0.00)$ & $(0.00)$ & (2.74e-05) \\
\hline \multirow[t]{2}{*}{ Constant } & $1.81 * * *$ & $1.63 * * *$ & 26.66 & $22.22 *$ & -0.62 \\
\hline & $(0.24)$ & $(0.23)$ & (21.14) & (13.23) & $(2.44)$ \\
\hline Regional Dummies & Yes & Yes & Yes & Yes & Yes \\
\hline Observations & 55 & 50 & 55 & 64 & 73 \\
\hline R-squared & 0.338 & 0.382 & 0.208 & 0.753 & 0.541 \\
\hline
\end{tabular}

Robust standard errors in parentheses $* * * \mathrm{p}<0.01, * * \mathrm{p}<0.05,{ }^{*} \mathrm{p}<0.1$ 
Table 8: Democracy

\begin{tabular}{|c|c|c|c|c|c|}
\hline & RATIO & RATIO & REPLACE & COVERAGE & PENSION \\
\hline VARIABLES & LOW & MEDIUM & & & SPENDING \\
\hline \multirow[t]{2}{*}{ Communitarian } & $-0.66 * *$ & $-0.54 * *$ & $44.77 * *$ & $-37.60 * * *$ & -3.72 \\
\hline & $(0.30)$ & $(0.24)$ & $(21.40)$ & (8.63) & (2.63) \\
\hline \multirow[t]{2}{*}{ Autoritarian } & $-0.33 *$ & $-0.35 * *$ & 17.42 & 0.71 & $2.24^{*}$ \\
\hline & $(0.18)$ & $(0.15)$ & (11.17) & (4.69) & (1.19) \\
\hline \multirow[t]{2}{*}{ Egalit Nuclear } & -0.33 & $-0.45 * * *$ & 28.93*** & $-9.37 * *$ & $2.44 *$ \\
\hline & $(0.20)$ & $(0.13)$ & (9.30) & (3.65) & (1.37) \\
\hline \multirow[t]{2}{*}{ polity2_1900 } & -0.00 & 0.00 & 0.11 & 0.44 & -0.09 \\
\hline & $(0.01)$ & $(0.00)$ & $(0.95)$ & $(0.36)$ & $(0.09)$ \\
\hline \multirow[t]{2}{*}{ Constant } & $1.75 * * *$ & $1.58 * * *$ & $48.09 * *$ & $60.68 * * *$ & $9.34 * * *$ \\
\hline & $(0.23)$ & $(0.19)$ & (18.91) & $(6.76)$ & $(2.57)$ \\
\hline Regional Dummies & Yes & Yes & Yes & Yes & Yes \\
\hline Observations & 34 & 33 & 34 & 39 & 45 \\
\hline R-squared & 0.265 & 0.355 & 0.275 & 0.863 & 0.535 \\
\hline
\end{tabular}

Robust standard errors in parentheses ${ }^{* * *} \mathrm{p}<0.01,{ }^{* *} \mathrm{p}<0.05,{ }^{*} \mathrm{p}<0.1$ 
Table 9: GDP and Share of Elderly

\begin{tabular}{|c|c|c|c|c|c|}
\hline & RATIO & RATIO & REPLACE & COVERAGE & PENSION \\
\hline VARIABLES & LOW & MEDIUM & & & SPENDING \\
\hline \multirow[t]{2}{*}{ Communitarian } & $-0.58 * * *$ & $-0.59 * * *$ & $38.07 * * *$ & $-14.76 * * *$ & 0.91 \\
\hline & (0.18) & $(0.14)$ & (11.53) & (4.59) & (1.43) \\
\hline \multirow[t]{2}{*}{ Autoritarian } & -0.20 & $-0.23^{*}$ & 12.51 & -4.33 & 0.46 \\
\hline & $(0.14)$ & (0.13) & (8.79) & (3.89) & (1.13) \\
\hline \multirow[t]{2}{*}{ Egalit Nuclear } & $-0.36 * *$ & $-0.48 * * *$ & $31.28 * * *$ & $-13.02 * * *$ & 2.24 \\
\hline & $(0.17)$ & $(0.12)$ & (8.84) & (4.15) & (1.35) \\
\hline Share of Elderly & $\begin{array}{l}-0.00 \\
(0.00)\end{array}$ & $\begin{array}{l}-0.00 \\
(0.00)\end{array}$ & $\begin{array}{c}0.05 \\
(0.97)\end{array}$ & $\begin{array}{c}2.65 * * * \\
(0.42)\end{array}$ & $\begin{array}{c}0.67 * * * \\
(0.10)\end{array}$ \\
\hline \multirow[t]{2}{*}{ Ln GPDpc } & -0.06 & -0.06 & $5.81 *$ & $5.65 * * *$ & 0.41 \\
\hline & $(0.04)$ & $(0.05)$ & (3.41) & (1.83) & $(0.32)$ \\
\hline \multirow[t]{2}{*}{ Constant } & $2.23 * * *$ & $2.13 * * *$ & -6.65 & -18.35 & $-4.45^{*}$ \\
\hline & $(0.48)$ & $(0.54)$ & (33.20) & (15.49) & $(2.50)$ \\
\hline Regional Dummies & Yes & Yes & Yes & Yes & Yes \\
\hline Observations & 54 & 49 & 54 & 65 & 75 \\
\hline R-squared & 0.350 & 0.393 & 0.204 & 0.885 & 0.742 \\
\hline
\end{tabular}

Robust standard errors in parentheses $* * * \mathrm{p}<0.01,{ }^{* *} \mathrm{p}<0.05,{ }^{*} \mathrm{p}<0.1$ 
Table 10: Electoral rules and forms of government

\begin{tabular}{|c|c|c|c|c|c|}
\hline & RATIO & RATIO & REPLACE & COVERAGE & PENSION \\
\hline VARIABLES & LOW & MEDIUM & & & SPENDING \\
\hline \multirow[t]{2}{*}{ Communitarian } & $-0.40 *$ & $-0.49 * *$ & 18.85 & $-36.62 * * *$ & $-3.31 *$ \\
\hline & $(0.20)$ & (0.19) & (11.57) & (10.75) & (1.66) \\
\hline \multirow[t]{2}{*}{ Autoritarian } & -0.09 & -0.18 & 0.36 & $-12.96 *$ & -1.37 \\
\hline & $(0.22)$ & $(0.20)$ & $(10.05)$ & (7.55) & $(1.42)$ \\
\hline \multirow[t]{2}{*}{ Egalit Nuclear } & -0.29 & $-0.44 * *$ & $19.11 * *$ & $-18.71^{* *}$ & 1.90 \\
\hline & (0.19) & $(0.16)$ & (7.29) & (7.11) & (1.54) \\
\hline Majoritarian & $\begin{array}{c}0.19 \\
(0.19)\end{array}$ & $\begin{array}{c}0.09 \\
(0.17)\end{array}$ & $\begin{array}{c}-17.50 * * * \\
(6.15)\end{array}$ & $\begin{array}{c}-15.60 * * \\
(7.45)\end{array}$ & $\begin{array}{c}-3.83 * * * \\
(1.00)\end{array}$ \\
\hline \multirow[t]{2}{*}{ Presidential } & -0.17 & -0.15 & 1.66 & -8.65 & -1.00 \\
\hline & $(0.16)$ & $(0.15)$ & (9.59) & (6.41) & $(0.67)$ \\
\hline \multirow[t]{2}{*}{ Constant } & $1.49 * * *$ & $1.52 * * *$ & $57.46 * * *$ & $77.94 * * *$ & $10.46^{* * *}$ \\
\hline & $(0.22)$ & (0.19) & $(13.24)$ & (10.69) & (1.79) \\
\hline Regional Dummies & Yes & Yes & Yes & Yes & Yes \\
\hline Observations & 41 & 39 & 41 & 46 & 52 \\
\hline R-squared & 0.257 & 0.339 & 0.255 & 0.736 & 0.584 \\
\hline
\end{tabular}

Robust standard errors in parentheses *** $\mathrm{p}<0.01,{ }^{* *} \mathrm{p}<0.05,{ }^{*} \mathrm{p}<0.1$ 
Table 11: Individual Preferences and strength of anecestors' family ties

\begin{tabular}{|c|c|c|c|c|}
\hline VARIABLES & $\begin{array}{c}(1) \\
\text { social security } \\
\text { spending } \\
\end{array}$ & $\begin{array}{c}(2) \\
\text { government } \\
\text { responsability } \\
\end{array}$ & $\begin{array}{c}\text { (3) } \\
\text { old age } \\
\text { spending } \\
\end{array}$ & $\begin{array}{c}(4) \\
\text { retirement benefit } \\
\text { spending } \\
\end{array}$ \\
\hline communitarian & $\begin{array}{c}-0.001 \\
(0.027)\end{array}$ & $\begin{array}{c}-0.284 * \\
(0.143)\end{array}$ & $\begin{array}{c}-0.201 * * * \\
(0.053)\end{array}$ & $\begin{array}{c}-0.246 * * * \\
(0.059)\end{array}$ \\
\hline authoritarian & $\begin{array}{l}-0.024 \\
(0.020)\end{array}$ & $\begin{array}{l}-0.150 \\
(0.098)\end{array}$ & $\begin{array}{c}-0.090 * \\
(0.052)\end{array}$ & $\begin{array}{l}-0.069 * \\
(0.036)\end{array}$ \\
\hline egalitarian nuclear & $\begin{array}{c}-0.066 * * \\
(0.032)\end{array}$ & $\begin{array}{c}-0.225^{*} \\
(0.111)\end{array}$ & $\begin{array}{c}-0.213^{* * *} \\
(0.029)\end{array}$ & $\begin{array}{c}-0.111 * * * \\
(0.034)\end{array}$ \\
\hline age & $\begin{array}{c}-0.013^{* * *} \\
(0.002)\end{array}$ & $\begin{array}{c}0.029 * * * \\
(0.008)\end{array}$ & $\begin{array}{c}-0.014^{* *} \\
(0.005)\end{array}$ & $\begin{array}{c}-0.014^{* *} \\
(0.005)\end{array}$ \\
\hline age squared & $\begin{array}{c}0.000 * * * \\
(0.000)\end{array}$ & $\begin{array}{c}-0.000 * * \\
(0.000)\end{array}$ & $\begin{array}{c}0.000^{* * *} \\
(0.000)\end{array}$ & $\begin{array}{c}0.000 * * * \\
(0.000)\end{array}$ \\
\hline male & $\begin{array}{c}0.126 * * * \\
(0.010)\end{array}$ & $\begin{array}{c}0.060 \\
(0.067)\end{array}$ & $\begin{array}{c}0.152 * * * \\
(0.015)\end{array}$ & $\begin{array}{c}0.115^{* * *} \\
(0.023)\end{array}$ \\
\hline income & $\begin{array}{l}0.007^{*} \\
(0.004)\end{array}$ & $\begin{array}{c}0.028 * * \\
(0.013)\end{array}$ & $\begin{array}{c}0.024 * * * \\
(0.004)\end{array}$ & $\begin{array}{c}0.031^{* * *} * \\
(0.007)\end{array}$ \\
\hline education & $\begin{array}{c}0.037 * * * \\
(0.006)\end{array}$ & $\begin{array}{c}0.075 * * * \\
(0.010)\end{array}$ & $\begin{array}{c}0.057 * * * \\
(0.006)\end{array}$ & $\begin{array}{c}0.074^{* * *} \\
(0.007)\end{array}$ \\
\hline liberal & $\begin{array}{c}-0.046 * * * \\
(0.009)\end{array}$ & $\begin{array}{l}-0.217 \\
(0.134)\end{array}$ & $\begin{array}{c}-0.218 * * * \\
(0.032)\end{array}$ & $\begin{array}{c}-0.097 * * \\
(0.041)\end{array}$ \\
\hline conservative & $\begin{array}{c}0.122 * * * \\
(0.010)\end{array}$ & $\begin{array}{c}0.241 * * * \\
(0.067)\end{array}$ & $\begin{array}{c}0.227 * * * \\
(0.040)\end{array}$ & $\begin{array}{c}0.145^{* * *} \\
(0.049)\end{array}$ \\
\hline unemployed & $\begin{array}{c}0.008 \\
(0.020)\end{array}$ & $\begin{array}{l}-0.344 \\
(0.216)\end{array}$ & $\begin{array}{l}-0.113 \\
(0.090)\end{array}$ & $\begin{array}{l}-0.144 \\
(0.118)\end{array}$ \\
\hline retired & $\begin{array}{c}-0.027 * * \\
(0.012)\end{array}$ & $\begin{array}{c}0.125 \\
(0.140)\end{array}$ & $\begin{array}{c}-0.012 \\
(0.070)\end{array}$ & $\begin{array}{l}-0.049 \\
(0.044)\end{array}$ \\
\hline other occupation & $\begin{array}{c}0.030 * * * \\
(0.011)\end{array}$ & $\begin{array}{c}0.054 \\
(0.071)\end{array}$ & $\begin{array}{l}-0.002 \\
(0.042)\end{array}$ & $\begin{array}{l}-0.016 \\
(0.047)\end{array}$ \\
\hline Constant & $\begin{array}{c}1.200 * * * \\
(0.110)\end{array}$ & $\begin{array}{c}0.584 * * \\
(0.237)\end{array}$ & $\begin{array}{c}1.014^{* * *} \\
(0.147)\end{array}$ & $\begin{array}{c}1.631^{* * *} \\
(0.142)\end{array}$ \\
\hline Year fixed effects & YES & YES & YES & YES \\
\hline Observations & 17,161 & 844 & 3,090 & 2,474 \\
\hline R-squared & 0.067 & 0.110 & 0.123 & 0.107 \\
\hline
\end{tabular}

Robust standard errors in parentheses *** $\mathrm{p}<0.01,{ }^{* *} \mathrm{p}<0.05,{ }^{*} \mathrm{p}<0.1$ 
Table 12: Individual Preferences in Finland, Portugal and the UK

\begin{tabular}{lccc}
\hline & $(1)$ & $(2)$ & $(3)$ \\
VARIABLES & UK & Portugal & Finland \\
\hline \multirow{2}{*}{ authoritarian } & $\mathbf{0 . 5 1 1 * * *}$ & $\mathbf{0 . 1 9 7}$ & $\mathbf{- 0 . 1 1 5}$ \\
age & $\mathbf{( 0 . 1 8 1 )}$ & $\mathbf{( 0 . 2 5 7 )}$ & $\mathbf{( 0 . 1 5 6 )}$ \\
& 0.029 & $-0.058^{*}$ & $0.077^{* * *}$ \\
age squared & $(0.027)$ & $(0.031)$ & $(0.029)$ \\
& -0.000 & $-0.000^{* *}$ & $-0.001^{* * *}$ \\
male & $(0.000)$ & $(0.000)$ & $(0.000)$ \\
& 0.043 & 0.043 & $-0.346^{* *}$ \\
Medium Education & $(0.176)$ & $(0.215)$ & $(0.156)$ \\
High Education & -0.083 & -0.054 & $-0.347^{* *}$ \\
& $(0.192)$ & $(0.305)$ & $(0.175)$ \\
Medium Income & -0.256 & -0.457 & -0.243 \\
High Income & $(0.263)$ & $(0.416)$ & $(0.236)$ \\
Left & -0.000 & -0.024 & $-0.354^{*}$ \\
& $(0.219)$ & $(0.261)$ & $(0.196)$ \\
Center & $-0.400^{*}$ & -0.325 & $-0.565^{* * *}$ \\
Constant & $(0.223)$ & $(0.314)$ & $(0.195)$ \\
& $0.764 * * *$ & & $1.187^{* * *}$ \\
Observations & $(0.274)$ & & $(0.228)$ \\
R-squared & & -0.323 & \\
\hline
\end{tabular}

Robust standard errors in parentheses *** $\mathrm{p}<0.01,{ }^{* *} \mathrm{p}<0.05,{ }^{*} \mathrm{p}<0.1$ 


\section{Figure 1: Family Types}

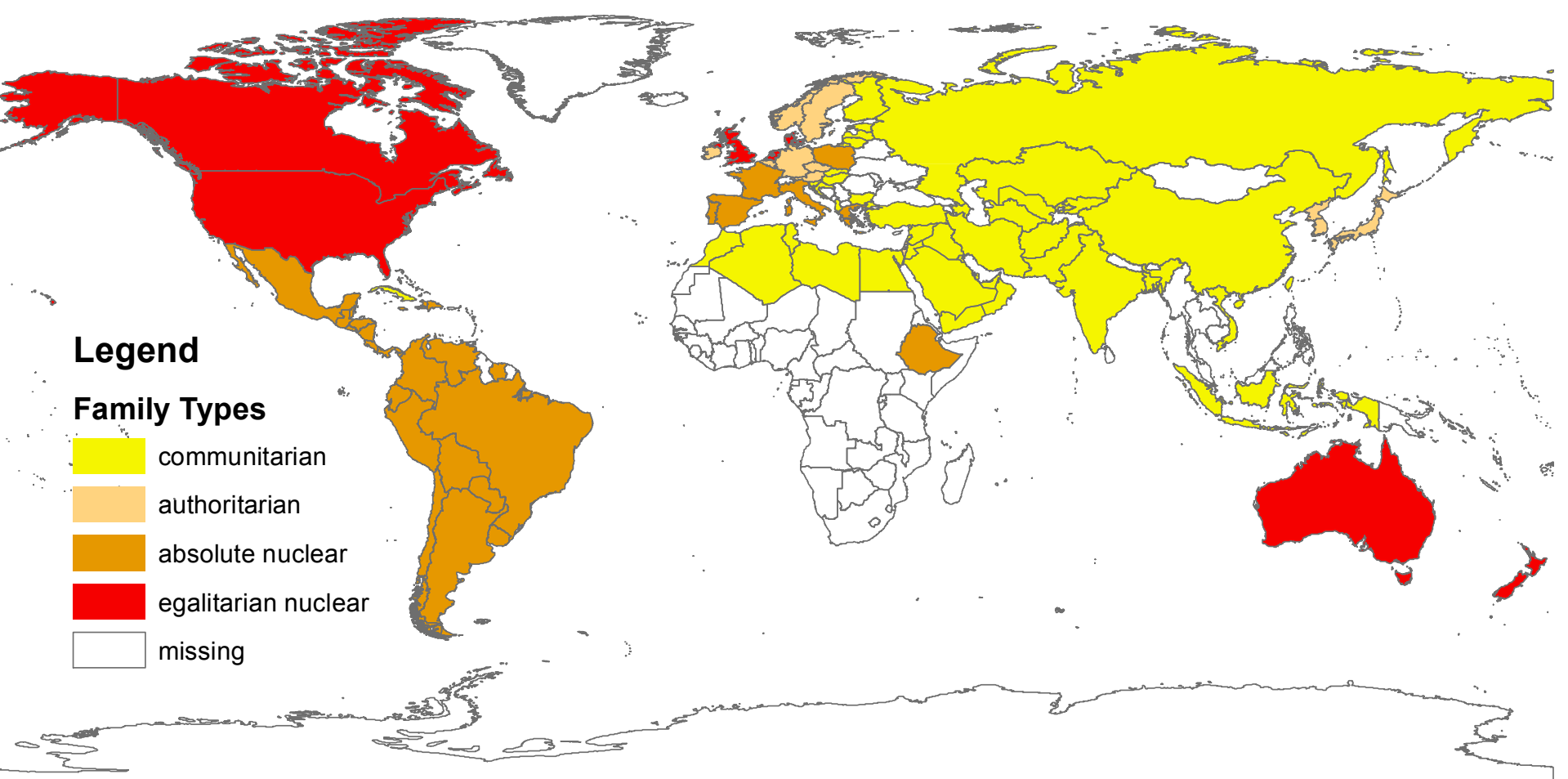


Figure 2: The Redistributive Design of Pensions: Low Ratio

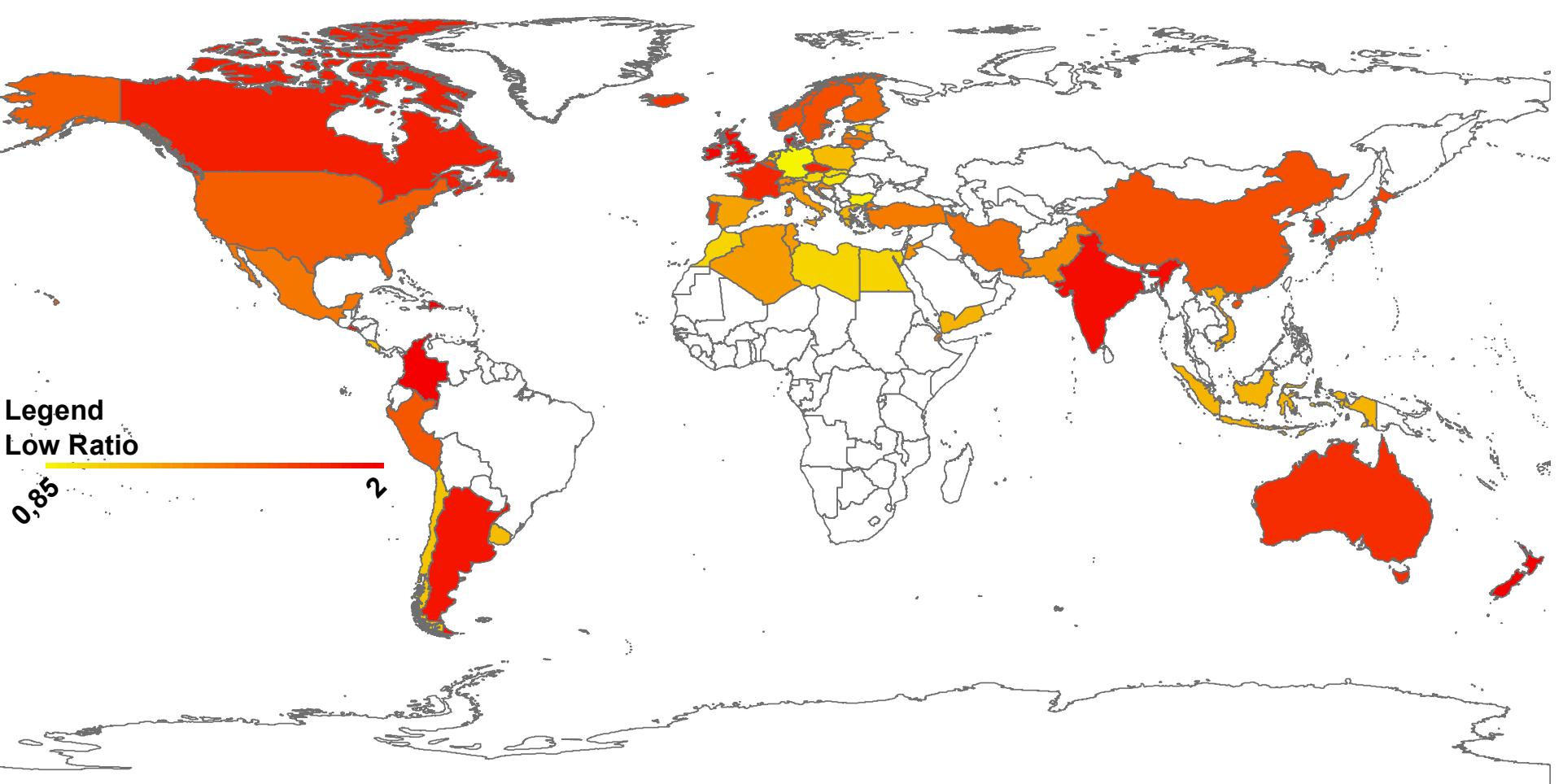


Figure 3: The Redistributive Design of Pensions: Medium Ratio

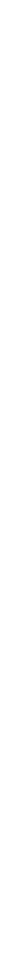


Figure 4: Legal Origins

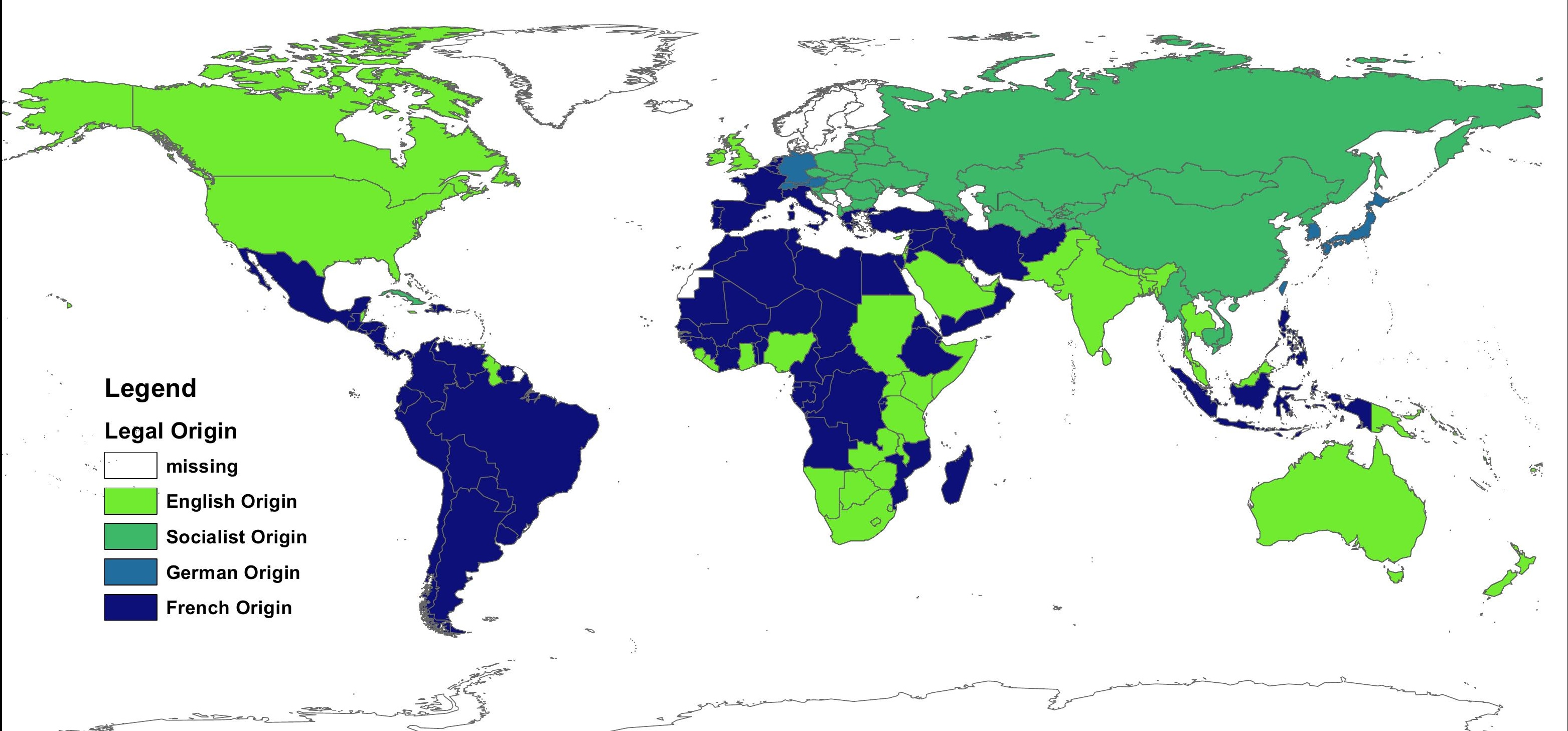




\section{CEPRA WORKING PAPER}

$01 / 2012$

V. Galasso, P. Profeta, When the state mirrors the family : the design of pension systems 